\title{
The evolution of commercial drug delivery technologies
}

\author{
Ava M. Vargason ${ }^{1}$, Aaron C. Anselmo $\oplus^{1 凶}$ and Samir Mitragotri $\circledast^{2,3 凶}$
}

Drug delivery technologies have enabled the development of many pharmaceutical products that improve patient health by enhancing the delivery of a therapeutic to its target site, minimizing off-target accumulation and facilitating patient compliance. As therapeutic modalities expanded beyond small molecules to include nucleic acids, peptides, proteins and antibodies, drug delivery technologies were adapted to address the challenges that emerged. In this Review Article, we discuss seminal approaches that led to the development of successful therapeutic products involving small molecules and macromolecules, identify three drug delivery paradigms that form the basis of contemporary drug delivery and discuss how they have aided the initial clinical successes of each class of therapeutic. We also outline how the paradigms will contribute to the delivery of live-cell therapies.

$\mathrm{D}$ elivery strategies have greatly helped convert promising therapeutics into successful therapies ${ }^{1-4}$. As the therapeutic landscape evolved, delivery strategies and technologies quickly adapted to reflect changing drug delivery needs. A few decades ago, small-molecule drugs were the primary class of therapeutic. Because the delivery of small molecules is largely dictated by their physicochemical properties, which heavily influence the bioavailabilities of the drugs, delivery efforts first focused on improving the solubility of the drugs, controlling their release, broadening their activity and adjusting their pharmacokinetics $(\mathrm{PKs})^{5,6}$. Over time, new generations of therapeutics, including proteins and peptides, monoclonal antibodies (mAbs), nucleic acids and live cells, have provided new therapeutic functions. The new functions brought about additional challenges, notably in stability (for proteins and peptides, in particular), intracellular delivery requirements (especially for nucleic acids) and viability and expansion (for live cells). Drug delivery strategies had to evolve to address these challenges.

In this Review Article, we evaluate how delivery challenges associated with the five classes of therapeutic-small molecules, nucleic acids, peptides, proteins and cells-led to the development of drug delivery approaches and of commercial products. By carrying out this analysis, we identify three core paradigms that have been used to overcome drug delivery challenges for each class of therapeutic (Fig. 1): modification of the drug itself; alteration of the environment around the drug; and creation of an interface (that is, a drug delivery system) that facilitates delivery by controlling the interactions between the drug and its microenvironment. For each paradigm, we outline how it can be used to push the boundaries of drug delivery and to address emerging challenges in the delivery of therapeutic live cells. We also discuss how the evolution of drug delivery technologies has been catalysed by each new class of therapeutic.

\section{Classes of therapeutic and delivery challenges}

For all drugs, the goal of delivery is to maximize therapeutic efficacy by transporting and releasing the drug (passively or actively) to the target site in the body and by minimizing off-target accumulation of the drug. This can be achieved by controlling drug PKs, reducing drug toxicity, increasing the accumulation of the drug at the target site and improving patient acceptance and compliance. Innovation in delivery technologies and strategies has been catalysed by the identification of unique delivery challenges associated with each class of therapeutic. In this section, we highlight the key innovations and their clinical and commercial successes (Table 1).

Small molecules. Small-molecule drugs ( $<900$ daltons) such as chemotherapeutics, antibiotics and steroids have been identified, developed and used as pharmaceuticals since the late $1800 \mathrm{~s}^{7}$. By virtue of their size, small-molecule drugs can rapidly diffuse through biological fluids, across many biological barriers and through cell membranes ${ }^{8}$. These advantages enable small molecules to navigate the complex vasculature and to interact with nearly all tissues and cell types in the body. However, for rapid diffusion and access to the systemic vasculature, small molecules must be freely soluble in biological fluids; hence, this limits (or hampers) the therapeutic utility of poorly soluble molecules ${ }^{9}$. About $90 \%$ of preclinical drug candidates are low-solubility compounds ${ }^{10}$, so this remains a challenge. Strategies to overcome low bioavailability focused on improving drug solubility by modulating the local microenvironment (in particular, via the use of $\mathrm{pH}$ modifiers for small molecules with considerable $\mathrm{pH}$-dependent solubility). This enabled clinical successes such as intravenous ciprofloxacin, which is formulated with lactic acid to improve its solubility via $\mathrm{pH}$ modulation $^{11}$. Other strategies focused on altering the small molecules themselves to modulate their physicochemical properties for improved solubilization, diffusion or absorption. For example, the angiotensin-converting-enzyme inhibitors benazepril (brand name, Lotensin) and enalapril (Vasotec) are commercially formulated with alkyl ester prodrugs that mask ionizable groups, thereby improving the absorption and bioavailability of the drug ${ }^{12}$. Meanwhile, the commercial formulation of the critical protease inhibitor for HIV treatment ritonavir (Norvir) is thiazole-modified to improve its metabolic stability and aqueous solubility ${ }^{13}$.

Fundamental efforts to understand drug transport through the vasculature and into tissues or cells led to the establishment of PK

'Division of Pharmacoengineering and Molecular Pharmaceutics, Eshelman School of Pharmacy, University of North Carolina at Chapel Hill, Chapel Hill, NC, USA. ${ }^{2}$ John A. Paulson School of Engineering and Applied Sciences, Harvard University, Cambridge, MA, USA. ${ }^{3}$ Wyss Institute for Biologically Inspired Engineering, Cambridge, MA, USA.『e-mail: aanselmo@email.unc.edu; mitragotri@seas.harvard.edu 
a

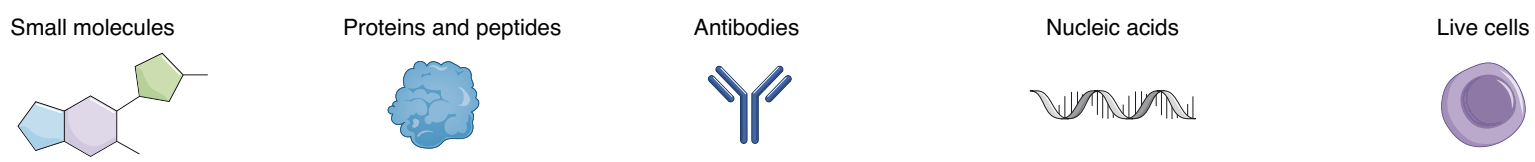

\begin{tabular}{|c|c|c|c|c|}
\hline \multicolumn{5}{|c|}{ Challenges } \\
\hline $\begin{array}{l}\text { Controlling PKs } \\
\text { Improving solubility } \\
\text { Improving permeability } \\
\text { Target development } \\
\text { Reducing off-target toxicity }\end{array}$ & $\begin{array}{l}\text { Controlling PKs } \\
\text { Improving stability } \\
\text { Non-invasive administration } \\
\text { Bypassing biological barriers } \\
\text { Reducing immunogenicity } \\
\text { Improving target selectivity }\end{array}$ & $\begin{array}{l}\text { Controlling PKs } \\
\text { Improving stability } \\
\text { Non-invasive administration } \\
\text { Bypassing biological barriers } \\
\text { Reducing immunogenicity } \\
\text { Achieving high doses }\end{array}$ & $\begin{array}{l}\text { Controlling PKs } \\
\text { Improving stability } \\
\text { Bypassing the target cell membrane } \\
\text { Accessing the cytosol or nucleus } \\
\text { Reducing immunogenicity } \\
\text { Preventing off-target gene editing }\end{array}$ & $\begin{array}{l}\text { Controlling unpredictable PKs } \\
\text { In vivo persistence and viability } \\
\text { Reducing immunogenicity } \\
\text { Maintaining therapeutic cell phenotype } \\
\text { Targeting to disease location } \\
\text { Manufacturing and scale-up }\end{array}$ \\
\hline
\end{tabular}

b
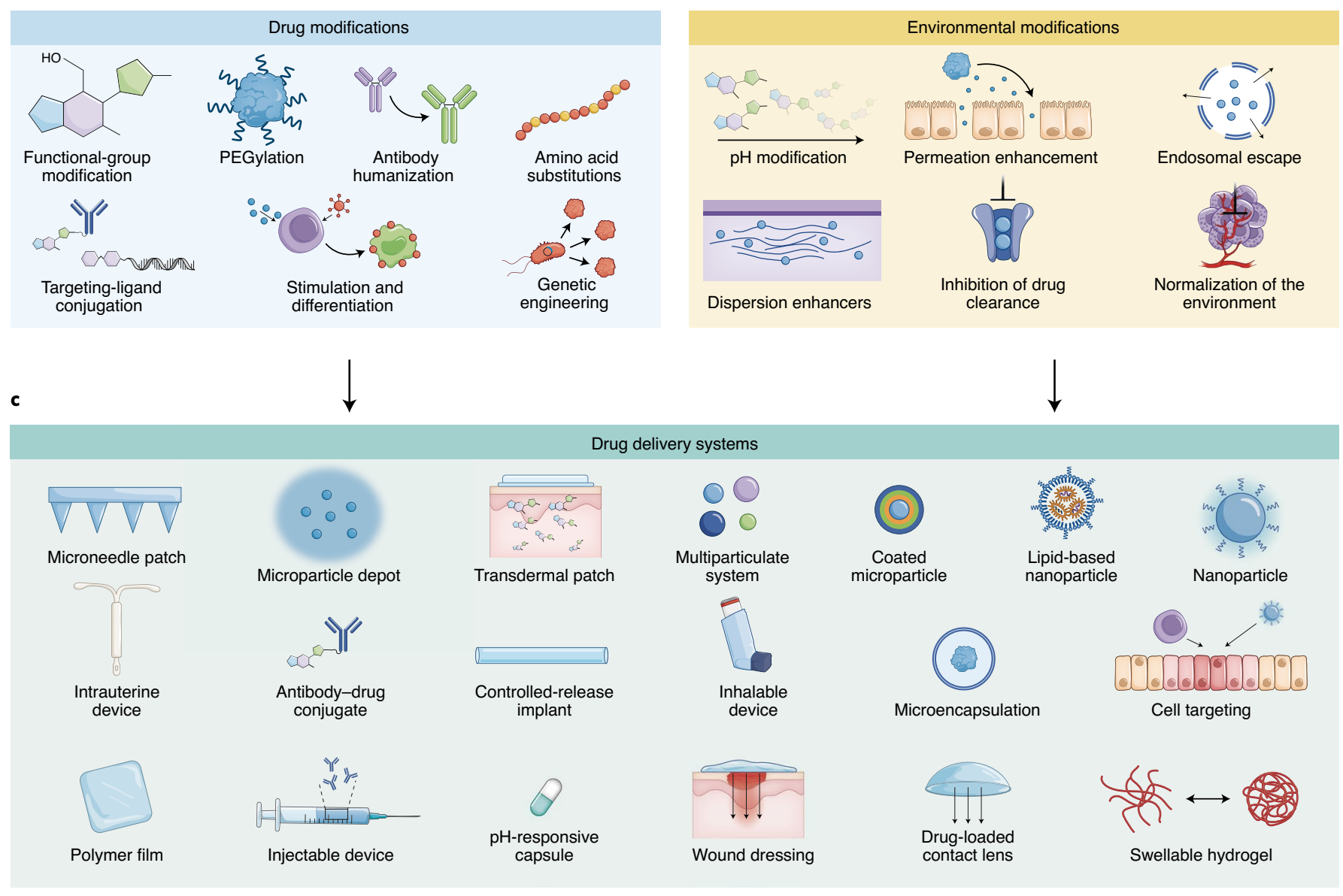

Fig. 1 | Classes of therapeutic and delivery paradigms. a, Each of the five generations of therapeutic (small molecules, proteins and peptides, antibodies, nucleic acids and cell therapies (live cells)) have their unique delivery challenges. b,c, These challenges have led to the development of the following delivery paradigms for improved therapeutic function: the modification of the drug or of its environment (b) and the design of drug delivery systems (c). Regardless of the class of therapeutic, drug delivery systems have adopted one or more strategies for drug modification or environmental modification.

and pharmacodynamic (PD) principles ${ }^{14-16}$. As the relationship between PK/PD parameters and the efficacy, duration of action and toxicity of small molecules became clearer, early efforts focused on controlling the dose and dosing regimen (that is, the frequency of infusion and infusion rate) to improve drug efficacy ${ }^{17,18}$. These seminal PK studies and clinical investigations laid the foundation for controlled-release drug delivery systems designed to achieve predictable drug release kinetics over a specified period using the following four mechanisms of drug release: dissolution, diffusion, osmosis and ion exchange ${ }^{19}$. Notably, regulators have approved at least 16 delivery systems based on osmotic release oral systems (the use of osmotic pumps reduces side effects associated with the wide variations in drug concentration that traditional dosing caused ${ }^{20}$ ).

Moreover, topically applied non-invasive controlled-release delivery systems, such as transdermal patches, have facilitated the long-term administration of analgesics and smoking-cessation agents, which improves patient compliance ${ }^{21}$. Additionally, systems based on nanoparticles and microparticles have been used to overcome solubility challenges, to enable the trafficking of small molecules to their site of action and to reduce off-target side effects. Nanoparticle therapeutics have been approved for a wide range of indications, from cancer treatment to vaccination ${ }^{22,23}$. The better 
Table 1 | Challenges for each class of therapeutic and examples of clinically relevant delivery technologies that addressed these challenges

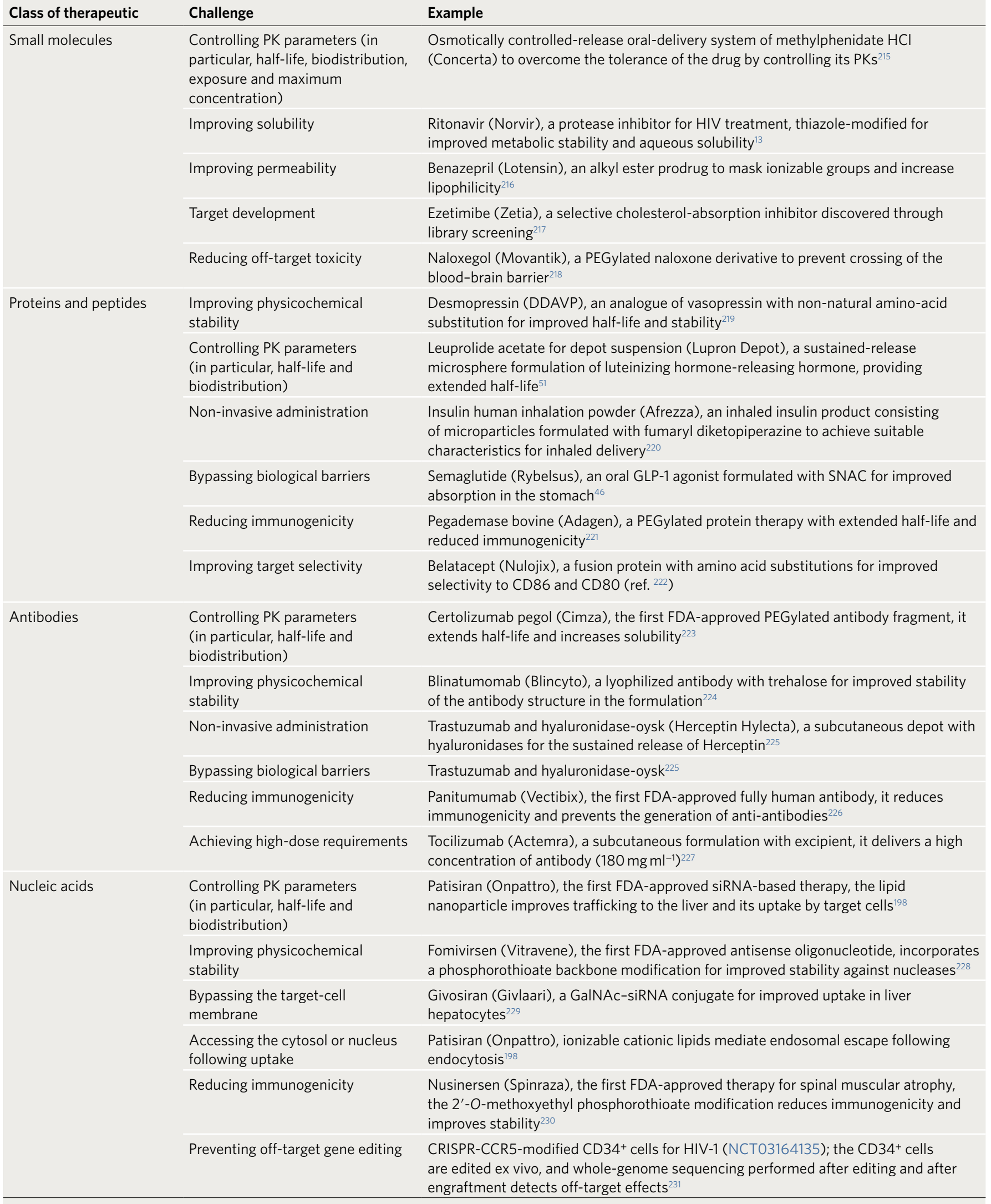


Table 1 | Challenges for each class of therapeutic and examples of clinically relevant delivery technologies that addressed these challenges (Continued)

\begin{tabular}{|c|c|c|}
\hline Class of therapeutic & Challenge & Example \\
\hline \multirow[t]{6}{*}{ Live-cell therapies } & $\begin{array}{l}\text { Controlling unpredictable PK } \\
\text { parameters }\end{array}$ & $\begin{array}{l}\text { Preclinical alginate-based biopolymer implants for the controlled release of CAR } \\
\text { T cells directly at the site of action }{ }^{204}\end{array}$ \\
\hline & In vivo persistence and viability & $\begin{array}{l}\text { SIG-001, factor-VIII-secreting genetically engineered cells in an antifibrotic matrix } \\
\text { (NCT04541628); it enables long-term cell persistence at the site of action }{ }^{203}\end{array}$ \\
\hline & Reducing immunogenicity & $\begin{array}{l}\text { Fludarabine conditioning chemotherapy for CAR T cells (NCT01865617); conditioning } \\
\text { chemotherapy reduces the immune rejection of infused cells }{ }^{232}\end{array}$ \\
\hline & $\begin{array}{l}\text { Maintaining therapeutic-cell } \\
\text { phenotype }\end{array}$ & $\begin{array}{l}\text { Sipuleucel-T (Provenge), the first FDA-approved cell-based (dendritic cell) } \\
\text { immunotherapy, induces and maintains a therapeutic phenotype through ex vivo } \\
\text { antigen presentation }^{105}\end{array}$ \\
\hline & Targeting to disease location & $\begin{array}{l}\text { Matrix-induced autologous chondrocyte implantation for the maintenance of } \\
\text { chondrocytes at the site of action }{ }^{233} \text {, the first FDA-approved cellularized-scaffold } \\
\text { product }\end{array}$ \\
\hline & Manufacturing and scale-up & $\begin{array}{l}\text { Tisagenlecleucel (Kymriah), the first FDA-approved CAR T-cell therapy, established the } \\
\text { manufacturing process for genetically engineered autologous cell therapies }{ }^{234}\end{array}$ \\
\hline
\end{tabular}

charge and surface material, in particular) on nanoparticle toxicity and PKs has enabled improved control over the delivery of nanoparticle-based therapeutics ${ }^{24-27}$. Notably, early efforts identified the use of poly(ethylene glycol) (PEG) coatings as an effective technique to extend the circulation half-life of particles and to increase particle retention at tumour sites (Box 1). This led to the formulation of PEGylated liposomal doxorubicin (Doxil) ${ }^{28,29}$, the first nanoparticle therapeutic approved (in 1995) by the US Food and Drug Administration (FDA). Nanoparticles have since been extensively studied preclinically to address the outstanding challenge of site-selective delivery. Delivery systems are now widely used to control solubility, dosing and other delivery parameters for small molecules, and have subsequently been applied to each of the other classes of therapeutic.

Proteins and peptides. Although the foundation of drug delivery was built on the design needs for small molecules, their targets only represent $2-5 \%$ of the human genome ${ }^{30,31}$. Hence, alternative classes of therapeutic were needed. Peptides (2-50 amino acids) and proteins (50 or more amino acids) have evolved with the human body to have excellent selectivity for specific protein targets. Indeed, their large size and diverse tertiary structures increase the points of contact with specific protein pockets, granting the peptides and proteins higher potency and reduced toxicity than many small molecules ${ }^{32-34}$. As the clinical use of peptides and proteins increased, unique challenges that limited their delivery emerged ${ }^{35,36}$. Although the complex structure of peptides and proteins improves their potency and selectivity (relative to the potency and selectivity of small molecules), it also contributes to their poor stability. In fact, they are readily degraded at ambient storage conditions, and, in vivo, are sensitive to the presence of ubiquitous proteases, physiological temperature and alterations in $\mathrm{pH}^{36}$. This is compounded by the rapid diffusion of stabilizing excipients in physiological fluids ${ }^{37}$. Furthermore, peptides and proteins can activate the immune system through the immunogenicity of antigens on the protein structure or via their degradation, aggregation or post-translational modification ${ }^{38}$. This typically leads to rapid drug clearance and to immunogenicity-driven adverse events ${ }^{39,40}$. To overcome the challenges arising from their structure, synthetic or humanized peptide analogues incorporate non-natural amino acids or are conjugated to chemical moieties known to improve the half-life, stability, receptor affinity or toxicity of the peptides or proteins (collectively referred to as drug-like properties) ${ }^{32,41,42}$. Clinical successes from these efforts are exemplified by desmopressin (DDAVP), an analogue of the natural peptide therapy vasopressin (Vasostrict) but with improved half-life and stability ${ }^{32}$. most successful strategies for reducing protein immunogenicity and for extending its half-life. PEG can shield immunogenic epitopes and increase the hydrodynamic diameter of the drug, thereby reducing its renal clearance and extending its circulation half-life ${ }^{43}$. Another strategy involves microenvironmental modulation via the introduction of protease inhibitors that interfere with the degradation of the peptide or protein in physiological fluids ${ }^{44}$. By virtue of their large size, peptides and proteins exhibit size-based limitations in the penetration of biological barriers ${ }^{45}$. This inspired the development of penetration enhancers (such as sodium $N$-[8-(2-hydroxybenzoyl) amino caprylate]; SNAC) that modulate the microenvironment to buffer local gastric $\mathrm{pH}$ or to actively improve transcellular absorption of the peptide or protein. This strategy contributed to the recent clinical approval of semaglutide (Rybelsus), the first oral glucagon-like peptide (GLP-1) ${ }^{46}$.

Additional efforts towards improving the stability of peptides and proteins in physiological fluids, as well as their transport across biological barriers, led to the development of non-invasive delivery systems for improved patient compliance and convenience ${ }^{47,48}$. The focus on non-invasive delivery and the challenges associated with non-invasive routes of administration (oral, transdermal, inhalation and mucosal delivery, in particular) has played a key role in driving innovation in drug delivery strategies for peptides and larger therapeutics. Notable non-invasive alternatives include the following examples: the oral delivery of cyclosporine in a self-emulsifying formulation that improved its solubility for increased bioavailability (Neoral); the use of permeation enhancers and $\mathrm{pH}$ modulators to increase the absorption of an oral GLP-1 analogue (Rybelsus); and the formulation of insulin with the small-molecule excipient fumaryl diketopiperazine to form microparticles suitable for inhaled delivery (Afrezza) ${ }^{49,50}$. Research into non-invasive delivery systems has led to a better understanding of the kinetics of drug action, the biological barriers that prevent systemic drug access and the use of delivery systems to overcome these challenges.

Controlled-release technologies used for small-molecule therapeutics have similarly been adapted for peptides. An example is the extended release of the peptide hormone leuprolide from a microparticle depot, which reduced the number of required subcutaneous injections, lessened side-effects, and led to a long-term market success (Lupron Depot) ${ }^{51}$. However, an outstanding delivery challenge is mimicking the natural host-regulated processes of peptide and protein secretion with stimuli-responsive delivery systems ${ }^{52}$. This is particularly important when the therapeutic replaces natural biological processes, such as the release of insulin in response to glucose fluctuation or the pulsatile release of hormones throughout the day ${ }^{53,54}$. 


\section{Box 1 | PEG as a versatile drug carrier and its clinical} challenges

Originally reported in 1859, PEG displays unique osmotic properties and high solubilities in both aqueous and organic solvents. Hence, it is used in a wide variety of industrial processes and in early intestinal-transit studies as an inert polymer and laxative ${ }^{235}$. PEG can bind a large number of water molecules, it is relatively safe to use in humans and it is widely used as a protein-conjugation polymer ${ }^{236-238}$. This PEGylation technique extends the circulation half-life of many proteins and reduces the generation of antibodies to them. The first PEGylated protein drugs were pegademase bovine and pegaspargase (Oncaspar ${ }^{239}$. Soon after, PEG was used to provide 'stealth' properties to liposomes. It led to their reduced uptake by the reticuloendothelial system ${ }^{240}$, and ultimately to the regulatory approval of the first nanotherapeutic: liposomal doxorubicin. More recently, the stealthiness of PEG has been used to improve the circulation half-life of lipid nanoparticles for siRNA (patisiran) ${ }^{198}$. The original use of PEG as a laxative has been repurposed as an environmental modulator for the improved engraftment of live bacterial therapeutics ${ }^{241}$, while PEGylation strategies are retroactively being applied to improve the delivery of small molecules by extending their half-life and improving their solubility. This led to the regulatory approval of naloxegol (Movantik) ${ }^{242}$.

Therefore, PEG exemplifies how a delivery strategy initially developed for a single class of therapeutic can have substantial impacts across a broader spectrum of therapeutics. However, pre-existing anti-PEG antibodies in patients can increase the clearance of PEGylated proteins $s^{243,244}$ and PEGylated particles ${ }^{245}$, which can increase the risk of immune-related adverse events ${ }^{246}$. In fact, the increasing use of PEGylated products in the clinic highlights the importance of evaluating the safety of the non-therapeutic components of delivery systems. Although the exact mechanism underlying PEG immunogenicity is unknown, it has been observed in both clinical and preclinical settings and has sparked research on the development of alternative non-fouling and immunologically inert polymers. These include synthetic polymer alternatives such as poly(2-oxazolines) and polypeptides with high zwitterion density ${ }^{247-249}$ as well as actively immune-modulatory peptides that mediate microenvironmental interactions ${ }^{250}$. Interestingly, these peptides use drug modification and environmental modification strategies that were first developed for proteins to actively prevent peptide clearance by circulating immune cells. In turn, developments to address PEG immunogenicity have led to delivery approaches that may be adapted for other immunogenic therapeutics ${ }^{251}$.

Antibodies. Antibodies are the predominant class of therapeutic, amounting to more than 500 ongoing clinical trials and more than 70 clinical approvals in the United States ${ }^{47,55}$. The structure of antibodies (which differs substantially from that of other classes of biologic) allows for specific interactions between therapeutic targets and the immune system (antibodies provide signals to the immune system by binding to cellular targets ${ }^{56}$ ). By binding to a target antigen, antibodies can neutralize it, preventing signalling molecules from binding to it and initiating (undesirable) cell processes $^{57}$. Additionally, antibodies can interact directly with host immune cells to initiate phagocytosis, antibody-dependent cellular cytotoxicity or complement-dependent cytotoxicity, triggering the death of undesirable cell populations ${ }^{58}$. However, the unique features of antibodies that enable these specific interactions can also lead to the development of anti-antibodies, which can cause adverse events such as rashes at the injection site, influenza-like symptoms and the development of autoimmune diseases ${ }^{59-61}$. This is exemplified by muromonab-CD3 (Orthoclone OKT3), the first clinically approved (in 1986) murine-derived mAb, which caused adverse events associated with both its mechanism of action and its recognition as a foreign antigen by the immune system ${ }^{62}$. The drug was discontinued in 2010 after more favourable treatments entered the market ${ }^{63}$. Subsequent approvals for antibody therapies stalled until the 2000s owing to the immunogenicity of mouse-derived antibodies $^{64}$. In the intervening decade, advances in antibody manufacturing that allowed for the modification of the antibody structure itself $^{65}$ enabled the production of daclizumab (Zinbryta), the first humanized therapeutic antibody, which is used for the treatment of adults with relapsing forms of multiple sclerosis, and of adalimumab (Humira), the first fully human antibody produced from display technologies ${ }^{66,67}$ and an anti-tumour-necrosis-factor (TNF) drug used to treat rheumatoid arthritis and many other inflammatory conditions. Additionally, directly modifying therapeutic antibodies through PEGylation, a strategy that was established for peptides and proteins, has improved antibody half-life and immunogenicity, and led to the clinical approval of certolizumab pegol (Cimzia) in 2008 (ref. ${ }^{68}$ ), which also binds to TNF and is used for the treatment of multiple chronic inflammatory conditions.

Because the PK/PD of antibodies can be highly variable, and their mechanism of action relies on engaging with the dynamic immune system, antibody treatments typically require high doses and invasive administration ${ }^{69}$. A delivery strategy involving the use of hyaluronidases to modulate the local microenvironment by remodelling the subcutaneous space enabled the subcutaneous administration of high doses of antibodies and their subsequent absorption. This strategy led to the commercialization of hyaluronidase-based depot injections ${ }^{70}$. Agents that restructure the tumour microenvironment have also been used to facilitate the penetration of antibody-based immunotherapies in solid tumours ${ }^{71}$. Notably, antibodies themselves have been clinically used to modify the microenvironment, as is the case with anti-vascular endothelial growth factor (VEGF) therapy for the normalization of the tumour vasculature ${ }^{72}$, and anti-PD-1 and anti-CTLA-4 checkpoint inhibitors for improving the immunosuppressive tumour microenvironment ${ }^{73}$. Nearly all microenvironment-modulating antibody-based therapies are used to improve or enable chemotherapeutic efficacy (as is the case for the anti-VEGF antibody bevacizumab (Avastin) ${ }^{74}$ ).

The introduction of antibodies as a therapeutic modality alongside continuous advancements in both small-molecule and antibody modifications led to the development of antibody-drug conjugates $(\mathrm{ADCs})^{75}$. ADCs combine antibodies with cytotoxic small molecules to enable the delivery of drugs in a highly targeted manner while providing synergistic immunomodulatory functions ${ }^{76}$. For example, the ADC ado-trastuzumab emtansine (Kadcyla) combines the humanized $\mathrm{mAb}$ trastuzumab (a human epidermal growth factor receptor 2 (HER2)-targeted treatment for breast cancer and stomach cancer) with the cytotoxic molecule DM1 (also known as mertansine). By directing their delivery to target tissues, antibodies have facilitated the clinical translation of small molecules (maytansinoids, auristatins and calicheamicins, in particular) that on their own would be too toxic for clinical use.

Nucleic acids. Although protein and peptide therapeutics have greatly expanded the number of druggable targets, nucleic acids enable the precise control of gene expression, and hence can be used to silence or repair aberrant genes and to drive expression of therapeutically relevant genes ${ }^{77}$. By virtue of the specific binding enabled by their nucleotide sequence, nucleic acids, and more recent gene-editing tools such as CRISPR, can be rationally designed to therapeutically manipulate the human genome ${ }^{78}$. The potential of nucleic acids was exemplified by the market approval (in 1998) of fomivirsen (Vitravene), an antisense oligonucleotide (ASO) therapy 
used for the treatment of cytomegalovirus retinitis in patients who are immunocompromised ${ }^{79}$. However, first-generation ASO therapies saw limited clinical success owing to insufficient levels of gene suppression, a consequence of the inherent challenges of nucleic acid delivery ${ }^{80}$.

Naked nucleic acids are susceptible to nuclease degradation, which limits their half-life. Also, the human immune system is adept at identifying and eliminating foreign RNA and $\mathrm{DNA}^{81,82}$. Moreover, to be effective, nucleic acids need to be delivered to the cytoplasm of the cell (for short interfering RNA (siRNA) and messenger RNA (mRNA)) or to its nucleus (for ASOs, DNA and CRISPR), thus requiring cell internalization and endosomal escape ${ }^{81}$. These challenges have led to innovations in modification chemistries to the nucleobases, the sugar rings and the $3^{\prime}$ and $5^{\prime}$ ends of nucleic acids. This has enabled resistance against nuclease degradation, reduced immunogenicity and improved interactions with target cells ${ }^{83,84}$. In 2016, nusinersen (Spinraza), a next-generation ASO, became the only clinically approved treatment for spinal muscular atrophy ${ }^{85}$

Preclinically, environmental manipulations have improved the intracellular targeting of nucleic acids. For example, nucleic acid carriers can buffer endosomal $\mathrm{pH}$ or form lipoplexes with the endosomal membrane, which results in endosomal escape and cytosolic delivery $^{86}$. Additionally, cell-penetrating peptides have been used to either destabilize or restructure the endosomal membrane to improve the intracellular delivery of nucleic acids ${ }^{87}$.

Altogether, fundamental knowledge of chemical modifications to nucleic acids and advances in drug delivery systems led to the following first clinical approvals of siRNA therapeutics: the lipid-based nanoparticle patisiran (Onpattro) in 2018 for the treatment of polyneuropathy in patients with hereditary transthyretin-mediated amyloidosis ${ }^{88,89}$, and the subcutaneously injected $N$-acetylgalactosamine (GalNAc) conjugate givosiran (Givlaari) in 2019 for the treatment of adults with acute hepatic porphyria ${ }^{90}$. These approvals represent an integration of drug delivery knowledge: Onpattro relied on early advances and mechanistic insights into the natural accumulation of nanoparticles in the liver ${ }^{91}$, and Givlaari resulted from extensive work on the use of galactose ligands to facilitate the intracellular trafficking of glycopeptides (and later, DNA vectors) in hepatocytes $^{92,93}$. Also, subcutaneous administration (originally developed for small molecules and extensively used for biologics) slows the systemic absorption of siRNA-GalNAc conjugates, thereby improving their plasma exposure ${ }^{94}$. The development of Onpattro also benefited from decades of research on liposomal formulations of small molecules (and the optimization of the size, charge and chemistry of lipid-based nanoparticles for human use) and on the utility of PEGylation (originally clinically used for liposomal doxorubicin) to improve drug $\mathrm{PKs}^{29,95,96}$. Most recently, advances in nucleic acid delivery have been highlighted by the emergency use authorization of COVID-19 vaccines based on chemically modified mRNA and delivered via lipid nanoparticles stabilized with PEG ${ }^{97,98}$ (Box 2).

Live-cell therapy. Live cells are the newest generation of therapeutics. Live-cell therapies take advantage of the natural therapeutic functions of some cell types to regulate or enable key biological processes. For example, pluripotent stem cells can restore and heal tissues $^{99}$, reprogrammed immune cells can leverage the immune system for vaccination and cancer treatment ${ }^{100,101}$, and microbes can interact with the microbiome to regulate mucosal immunity, metabolic processes and chronic inflammatory processes ${ }^{102}$. Living cells can also be engineered. The most prominent example is chimeric antigen receptor (CAR) T cells. Clinically approved in 2017, they are genetically engineered cytotoxic T cells targeted to specific cancer-associated antigens ${ }^{103}$. In fact, CAR T-cell therapies highlight the functions and advantages of cell therapies: an innate ability to target sites of disease, potent activity at the site of action and the capacity to directly interface with the immune

\section{Box 2 | Drug delivery for COVID-19 therapeutics and vaccines}

The COVID-19 pandemic, caused by the SARS-CoV-2 coronavirus, has highlighted the importance of cross-disciplinary collaboration to rapidly develop (within months) effective treatments and vaccines ${ }^{252,253}$ as well as delivery technologies for them. Many vaccine candidates for COVID-19 entered clinical trials at an unprecedented pace ${ }^{254-256}$, in part enabled by the repurposing of delivery systems developed for other therapeutics ${ }^{25}$ (oncological drugs, in particular). Vaccine delivery systems have used controlled-release strategies to prevent the need for multiple rounds of injections ${ }^{258}$ as well as non-invasive delivery to facilitate patient acceptance and widespread availability ${ }^{259,260}$. In particular, mRNA vaccines and DNA vaccines can be effective tools for responding to emergent infectious diseases because these vaccines can be rapidly synthesized in vitro and can rely on modular delivery systems with plug-and-play designs ${ }^{98}$. This is the case of the first two COVID-19 vaccines approved for emergency use in the United States (mRNA-1273, developed by Moderna, and BNT162b2, by Pfizer in collaboration with BioNTech), which use a nucleoside-modified mRNA encoding for the prefusion-stabilized SARS-CoV-2 spike protein ${ }^{97,98}$. The delivery system for these vaccines is a lipid nanoparticle with ionizable cationic lipids, and was developed on the back of decades of work in technologies for the delivery of siRNA and mRNA ${ }^{261-263}$. The need for the rapid development of vaccines and for improved global access to vaccines has also motivated the development of other delivery technologies. In particular, the DNA vaccine INO-4800 (developed by Inovio) uses a device to facilitate the intradermal delivery of the vaccine via electroporation ${ }^{264}$.

COVID-19 has heightened the need for universal vaccines and treatments that can raise immune responses to classes of pathogen rather than to a single pathogen ${ }^{265}$. Live-cell therapies may be uniquely suited to address this; notably, two therapies (a living CD4 ${ }^{+}$T-helper 1 memory cell activated by attached CD3/CD28-coated microbeads and engineered to express type-1 inflammatory cytokines and immunomodulatory molecules, Allostim, by Immunovative Therapies; and allogeneic 'off the shelf' cardiosphere-derived cells, CAP-1002, by Capricor) are being clinically investigated as universal immunomodulators for improving patient responses to SARS-CoV-2 and other pathogens in patients with severe disease ${ }^{266,267}$ (NCT04623671, NCT00558675).

system and to proliferate in vivo ${ }^{104}$. Other FDA-approved adoptive cell therapies are sipuleucel-T (Provenge; for treating prostate can$\operatorname{cer}^{105}$ ) and cord-blood-derived stem cells ${ }^{106}$. Cells can also be engineered to secrete drugs or to catalyse key biological reactions, and hence can be used as drug factory depots. Genetically engineered drug-secreting depots, which are beginning to be tested in clinical trials, protect unstable biologics during transit and can mimic natural pulsatile or stimuli-responsive delivery profiles ${ }^{107}$.

The delivery of live cells poses unique challenges. Cells are substantially larger than all other classes of therapeutic, and hence can be rapidly entrapped in lung capillaries and eliminated ${ }^{108}$. For adoptive cell therapies (and for immunotherapies in particular), the size of the live cells and the hostile tumour microenvironment result in the low penetration of the cells in solid tumours. This has limited their current clinical use to haematological malignancies ${ }^{109}$. Moreover, the viability, persistence and maintenance of efficacious cellular phenotypes is heavily dependent on the environment and host of the delivered live cells $s^{110,111}$. There are also pragmatic concerns associated with the large-scale production of therapeutic live 
cells. On the one hand, autologous therapies have more favourable safety profiles, but require extraction, processing and re-infusing into the same patient, which limits the scalability of the therapy ${ }^{112,113}$. On the other hand, allogeneic therapies can be scaled more easily, but need cold-chain storage and shipment, and have stringent biocompatibility and sterility requirements ${ }^{114}$. For instance, Provenge, which in 2010 became the first approved autologous cellular immunotherapy, is produced by exposing immune cells from a patient to a recombinant human protein in culture conditions to stimulate and direct the cells against the prostate cancer of the patient after re-administration ${ }^{105}$. After regulatory approval, Provenge faced challenges related to its manufacturing and administration, and its high cost and short shelf-life prevented widespread clinical adoption $^{115}$. Similar challenges need to be overcome for many other live-cell therapies ${ }^{116}$.

We expect that clinically relevant drug delivery technologies will improve cell therapies within the next decade. A few of the promising strategies tested in animals are the identification of materials that improve the engraftment of $\beta$-cells for diabetes treatment ${ }^{117}$, hitchhiked nanoparticles that modify the tumour microenvironment for adoptive T-cell therapy ${ }^{118,119}$ and the genetic engineering of stem cells to serve as personalized chemotherapeutic factories ${ }^{120}$.

\section{Three paradigms of drug delivery}

We identified three core paradigms of drug delivery that span all classes of therapeutic: drug modifications, microenvironment modifications and drug delivery systems. In this section, we highlight their historical use throughout generations of therapeutics and discuss how this collective knowledge can be applied to cell therapies.

Drug modifications. The modification of a drug encompasses chemical alterations to its structure (such as to functional groups, amino acids or nucleic acid backbones) and its conjugation to known moieties or targeting ligands. The purpose is to modulate interactions between the drug and molecules, cells and tissues in the body as well as between the drug and its target site, allowing for some control over how the drug navigates and is processed within the body, from initial administration down to its intended function. Drug modifications have been used to improve the delivery for all classes of therapeutic (Table 2).

The physicochemical properties of small molecules have long been modified via the addition of known molecular entities or by directly altering the chemical structures of the molecules. Early work led to molecular-modification techniques for the synthesis of compounds with superior therapeutic action. Examples are lidocaine (an isogramine derivative with improved potency, toxicity and duration of action ${ }^{121}$ ) and fentanyl (a highly potent opioid with a therapeutic index superior to those of morphine and its parent compound meperidine $e^{122,123}$ ). This laid the foundation for medicinal chemistry, which contributed to high-throughput screening technologies that allowed for the rational design and selection of ideal molecular properties ${ }^{124}$ and led to general structure-function guidelines, such as the Lipinski's rule of five for the identification of suitable small-molecule pharmaceuticals ${ }^{125}$. As newer therapeutics with distinct molecular structures were introduced, previous approaches were adapted and new strategies created. For example, high-throughput screening has also been applied to therapeutic peptides and proteins, with desirable properties typically identified via large recombinant libraries chemically synthesized using display technologies ${ }^{126,127}$. Peptides and proteins also required new modification strategies, notably the conjugation of PEG to improve circulation time and immunogenicity ${ }^{128}$. Drug modifications have been particularly important for the delivery of insulin. For example, long-acting formulations such as insulin glargine (Lantus), a modified human insulin with $\mathrm{pH}$-dependent solubility that forms microprecipitates in the subcutaneous space, and degludec (Tresiba), an acylated insulin analogue that forms high-molecular-weight complexes, were made possible via rational modifications to the structure of insulin ${ }^{129,130}$. In these formulations, insulin monomers are slowly released from a subcutaneous depot, thus mimicking aspects of natural host-mediated insulin secretion, reducing injection frequency and the risk of hypoglycaemia and improving glycaemic control $^{131}$.

Production techniques for antibody therapeutics have evolved from mouse immunization to phage display, which has enabled the identification of biocompatible therapeutics ${ }^{132}$. The advancement of mAb technology has contributed to the recent successes of ADCs in addressing the cytotoxicity, off-target toxicity and lack of tissue-specific delivery of many small-molecule drugs ${ }^{133}$. The formulation of ADCs has benefited from drug-modification techniques developed for small molecules and antibodies.

Nucleic acid therapies have also benefitted from previous conjugation strategies, as evidenced by the recent approval of the GalNAcsiRNA conjugate Givlaari. Conjugate chemistries for nucleic acids have relied on a mix of previously established bio-orthogonal click-chemistry reactions and on the incorporation of conjugate molecules as non-nucleoside monomers during oligonucleotide synthesis $^{134}$. In particular, chemical modifications developed for the $2^{\prime}$ hydroxyl group of the ribose, for the polyadenylation of the $3^{\prime}$ end and for the replacement of the phosphodiester linkage enabled control over the action of nucleic acid drugs ${ }^{85}$.

Overall, drug modifications have enabled new functionalities for all classes of therapeutic by stabilizing them in physiological fluids, by controlling their interactions on individual cells and in them and by modifying their interaction with their pharmaceutical target. Drug modifications have evolved to address the changing structural complexity, specificity and function of each class of therapeutic and are now applied and further developed for cell therapies.

Efforts to modify live-cell therapies to improve their delivery have focused on the following aspects: altering cell function through genetic engineering; exposing cells to external stimuli ex vivo to facilitate phenotype differentiation or antigen presentation to immune cells; and modifying the surface of the cells via conjugation (cellular hitchhiking) of a drug to enhance therapeutic action. These three areas represent adaptations of knowledge of drug-modification strategies developed for previous generations of therapeutics. For instance, by taking advantage of natural cell-homing processes and by using live cells as an active delivery vehicle, nanoparticle 'backpacks' on circulating blood cells can be delivered directly to disease sites ${ }^{135,136}$. Alternatively, cellular hitchhiking can be used to support the in vivo expansion and survival of CAR T cells or of haematopoietic stem and progenitor cells through the release of adjuvants ${ }^{118,119}$. These strategies rely on the ability to chemically modify the surface of cells without impairing their viability or proliferative potential, often using conjugation strategies earlier deployed for the PEGylation of protein drugs (as in $N$-hydroxysuccinimide ester crosslinking ${ }^{118,137}$ ), and have built on earlier uses of cells as drug carriers ${ }^{138}$. As new therapeutic functions and drugs are introduced alongside advances in delivery and biological manipulation (such as cell-surface conjugation strategies ${ }^{139}$ ), new applications of cellular hitchhiking ${ }^{136,140,141}$ are expected.

In addition to conjugation strategies, the use of genetically engineered cells as both delivery vehicles and as in situ drug-secreting factories to replace the systemic delivery of small molecules, proteins and peptides is promising ${ }^{142}$. Moreover, cells can be exposed to stimuli ex vivo to induce a natural phenotypic shift without the need for genome engineering. For example, the differentiation of stem cells can induce secretion of the biologic, and the stimulation of immune cells can promote antigen presentation. Modifications to cells can also address outstanding challenges in the site-selective and tissue-selective delivery of small molecules with pronounced off-target toxicity ${ }^{143}$. In fact, some engineered cells have been 
Table 2 | Drug modifications and selected clinical examples

\begin{tabular}{|c|c|}
\hline Class of therapeutic & Modification \\
\hline \multirow[t]{5}{*}{ Small molecules } & Modification of functional groups \\
\hline & Masking undesirable chemical groups \\
\hline & $\begin{array}{l}\text { High-throughput and combinatorial chemistry } \\
\text { libraries }\end{array}$ \\
\hline & Conjugation of targeting ligands \\
\hline & PEGylation \\
\hline \multirow[t]{5}{*}{ Peptides and proteins } & Alterations to the amino acid sequence \\
\hline & Alteration of intramolecular bonding \\
\hline & Addition of non-natural amino acids \\
\hline & Chemical backbone modifications \\
\hline & PEGylation \\
\hline \multirow[t]{6}{*}{ Antibodies } & $\begin{array}{l}\text { Affinity maturation and variable-region } \\
\text { engineering }\end{array}$ \\
\hline & Antibody humanization \\
\hline & $\begin{array}{l}\text { Modification of Fc binding to the neonatal Fc } \\
\text { receptor }\end{array}$ \\
\hline & $\begin{array}{l}\text { Modification of antigen binding for } \mathrm{pH} \\
\text { responsiveness }\end{array}$ \\
\hline & Conjugation to PEG \\
\hline & Conjugation to small molecules \\
\hline \multirow[t]{3}{*}{ Nucleic acids } & $\begin{array}{l}\text { Codon optimization and chemical nucleotide } \\
\text { modifications }\end{array}$ \\
\hline & Chemical backbone modifications \\
\hline & Conjugation to targeting ligands \\
\hline \multirow[t]{4}{*}{ Live-cell therapies } & Surface conjugation \\
\hline & $\begin{array}{l}\text { In situ delivery of nucleic acids for host-cell } \\
\text { reprogramming }\end{array}$ \\
\hline & Exposure to external stimuli \\
\hline & Genetic engineering \\
\hline
\end{tabular}

effective preclinically as cancer-homing delivery vehicles for chemotherapeutics ${ }^{144}$ or as stimuli-responsive systems for the delivery of biologics; for example, insulin-producing cells have been engineered to respond to blood glucose levels ${ }^{145}$. Most recently, nucleic-acid-based delivery strategies such as viral-vector-mediated CRISPR-Cas9 genome editing have been applied to the ex vivo editing of live cells, and there are early clinical signs of the suitability of live-cell therapies for the treatment of sickle cell disease (ClincalTrials.gov identifier NCT03745287). Alternatively, existing delivery modalities such as nucleic-acid-loaded nanoparticles have been used as vehicles to reprogramme host cells in situ as factories for biologics and to overcome delivery challenges associated with cell therapies, including the navigation of biological barriers ${ }^{146-149}$.

We envision that a combination of genome editing, the application of external stimuli and surface conjugation will be used to enable stimuli-responsive, actively targeted and self-sustaining live-cell therapies. The potential for combining these cell-modification strategies was recently illustrated in the use of cellular backpacks for the modulation of the antitumour phenotype of macrophages after adoptive cell therapy ${ }^{150}$. By using the controlled secretion of cytokines from cellular backpacks, macrophages were continuously primed in situ to maintain an efficacious phenotype in the immunosuppressive tumour microenvironment, which in turn improved the survival and metastatic burden in mice. Cell-hitchhiking strategies are currently being tested in a clinical trial (NCT03815682)
Example

Ritonavir (Norvir)
Benazepril (Lotensin)
Ezetimibe (Zetia)
Vintafolide (NCT00511485)
Naloxegol (Movantik)
Belatacept (Nulojix)
Cyclosporine A (Sandimmune)
Desmopressin (DDAVP)
Cyclosporine A
Pegademase bovine (Adagen)
Ramucirumab (Cyramza), obinutuzumab (Gazyva)
Daclizumab (Zinbryta), panitumumab (Vectibix)
MEDI4893 (NCT02296320), Ravulizumab (Ultomiris)

Ravulizumab

\section{Certolizumab pegol (Cimzia)}

Brentuximab vedotin (Adcetris)

Patisiran (Onpattro), givosiran (Givlaari), nusinersen (Spinraza)

Fomivirsen (Vitravene), givosiran

Givosiran

PRIME ${ }^{\mathrm{LL}-15} /$ RPTR-147 (NCT03815682)

Janssen COVID-19 vaccine, recombinant p53 adenovirus (Gendicine)

Sipuleucel-T (Provenge)

Tisagenlecleucel (Kymriah), CTX001 (NCT03745287), RTX-240 (NCT04372706)

with the T-cell therapeutic PRIME ${ }^{\mathrm{IL}-15} / \mathrm{RPTR}-147$; this therapy tethers interleukin-15 (IL-15) nanoparticles to the surface of T cells to act as an immunostimulatory agent in patients with either solid tumours or lymphomas ${ }^{151}$.

Microenvironmental modifications. Modifications to the environment encompass a spectrum of approaches, from highly targeted changes at the site of action to systemically administered adjuvants that alter the host environment. Collectively, environmental modifications represent a broad drug delivery strategy that can aid in the navigation of biological barriers (Table 3 ).

For small molecules, excipients were developed to enhance drug solubility in physiological fluids by altering the local $\mathrm{pH}^{152-154}$. For biologics, given their larger size and the limitations that this imposes on the crossing of epithelial barriers, permeation enhancers, subcutaneous dispersion enhancers and other environmental modifiers were needed to facilitate the systemic absorption of biologics ${ }^{44,70}$. For nucleic acids, their entry into intracellular compartments limits their interactions with gene targets; hence, previous strategies were adapted to modify endosomal $\mathrm{pH}$, and cell-penetrating peptides and cationic lipids were introduced to improve intracellular uptake, endosomal escape and nuclei targeting ${ }^{155,156}$. These approaches facilitated the recent clinical translation of the siRNA therapeutic Onpattro, which uses ionizable cationic lipids to aid the restructuring of the endosome after endocytosis and the escape of the siRNA into the cytosol ${ }^{157,158}$. 


\begin{tabular}{|c|c|c|}
\hline $\begin{array}{l}\text { Class of } \\
\text { therapeutic }\end{array}$ & Modification & Example \\
\hline \multirow[t]{3}{*}{ Small molecules } & $\begin{array}{l}\text { Addition of } \\
\text { solubilizing excipients }\end{array}$ & Ciprofloxacin (Cipro IV) \\
\hline & $\begin{array}{l}\text { Inhibition of clearance } \\
\text { pathways }\end{array}$ & $\begin{array}{l}\text { Co-administration of } \\
\text { penicillin and probenecid }\end{array}$ \\
\hline & $\begin{array}{l}\text { Inhibition of drug } \\
\text { metabolism }\end{array}$ & Not yet in clinical trials \\
\hline \multirow[t]{5}{*}{$\begin{array}{l}\text { Peptides and } \\
\text { proteins }\end{array}$} & $\begin{array}{l}\text { Use of protease } \\
\text { inhibitors }\end{array}$ & Calcitonin-salmon (TBRIA) \\
\hline & Use of $\mathrm{pH}$ modifiers & $\begin{array}{l}\text { Semaglutide (Rybelsus), } \\
\text { calcitonin-salmon }\end{array}$ \\
\hline & $\begin{array}{l}\text { Use of permeation } \\
\text { enhancers }\end{array}$ & $\begin{array}{l}\text { Semaglutide, octreotide } \\
\text { (Mycapssa) }\end{array}$ \\
\hline & $\begin{array}{l}\text { Use of } \\
\text { immunomodulators }\end{array}$ & $\begin{array}{l}\text { Enzyme replacement } \\
\text { therapy co-administered } \\
\text { with methotrexate in Pompe } \\
\text { disease }\end{array}$ \\
\hline & Use of hyaluronidases & $\begin{array}{l}\text { Hylenex administration with } \\
\text { insulin (NCT01848990) }\end{array}$ \\
\hline \multirow[t]{5}{*}{ Antibodies } & $\begin{array}{l}\text { Use of enzyme } \\
\text { inhibitors }\end{array}$ & Not yet in clinical trials \\
\hline & Use of $\mathrm{pH}$ modifiers & Adalimumab (Humira) \\
\hline & $\begin{array}{l}\text { Use of permeation } \\
\text { enhancers }\end{array}$ & Not yet in clinical trials \\
\hline & $\begin{array}{l}\text { Use of } \\
\text { immunomodulators }\end{array}$ & $\begin{array}{l}\text { Infliximab (Remicade) } \\
\text { co-administered with } \\
\text { methotrexate }\end{array}$ \\
\hline & $\begin{array}{l}\text { Use of dispersion } \\
\text { enhancers }\end{array}$ & $\begin{array}{l}\text { Trastuzumab and } \\
\text { hyaluronidase-oysk } \\
\text { (Herceptin Hylecta) }\end{array}$ \\
\hline \multirow[t]{3}{*}{ Nucleic acids } & $\begin{array}{l}\text { Use of } \\
\text { immunomodulators }\end{array}$ & $\begin{array}{l}\text { Patisiran (Onpattro), } \\
\text { givosiran (Givlaari) }\end{array}$ \\
\hline & $\begin{array}{l}\text { Use of endosomal-pH } \\
\text { modifiers }\end{array}$ & Not yet in clinical trials \\
\hline & $\begin{array}{l}\text { Use of } \\
\text { endosomal-release } \\
\text { agents }\end{array}$ & Patisiran \\
\hline \multirow[t]{3}{*}{ Live-cell therapies } & $\begin{array}{l}\text { Use of signalling } \\
\text { molecules to support } \\
\text { in vivo cellular action }\end{array}$ & $\begin{array}{l}\text { Constitutive IL-12-secreting } \\
\text { CAR T cells (NCT02498912) }\end{array}$ \\
\hline & $\begin{array}{l}\text { Modification } \\
\text { of the tumour } \\
\text { microenvironment } \\
\text { (normalization of } \\
\text { vascularization, } \\
\text { substrate depletion } \\
\text { or modification of the } \\
\text { extracellular matrix) }\end{array}$ & $\begin{array}{l}\text { EGFR-IL-12 CAR T cells } \\
\text { (NCT03542799) }\end{array}$ \\
\hline & $\begin{array}{l}\text { Use of } \\
\text { immunomodulators }\end{array}$ & $\begin{array}{l}\text { TGF- } \beta \text {-insensitive CAR T cells } \\
\text { (NCT03089203), RTX-240 } \\
\text { (NCT04372706) }\end{array}$ \\
\hline
\end{tabular}

Modulators of the microenvironment can also be used to alter physiological fluids or mechanical processes that hinder drug action. For small-molecule drugs, a set of defined excipients have been developed to improve the uptake of the drugs in the small intestine by extending the intestinal transit time or by increasing their blood circulation time via the active inhibition of specific metabolic mechanisms ${ }^{153,154}$. For proteins and peptides, $\mathrm{pH}$ modifiers such as citric acid were repurposed from small-molecule solubilizers to inhibit proteolysis and to improve the stability of proteins and peptides in physiological fluids ${ }^{159}$. Additionally, systemically administered steroids have been used to modulate the immune environment and to prevent adverse reactions to protein therapeutics and nucleic acid therapies ${ }^{89,160}$. Collectively, environmental modifications can direct the passage of therapeutics through biological barriers and improve their efficacy in diseased tissues. These modifications, whether targeted or systemic, are now being applied to live-cell therapies.

Cell therapies require knowledge of how to precisely tune the microenvironment to improve their trafficking to the target site (and hence their efficacy). Also, the gene-expression profile of cells (and hence their phenotype) can shift in response to signals from the environment. Clinically, microenvironmental strategies have been applied to CAR T-cell therapy to address challenges associated with solid tumours, such as a hostile microenvironment with high interstitial pressure, abnormal vasculature and suppressive immune signalling $^{161}$. In particular, early clinical trials of CAR T cells administered cytokines systemically to restructure the immunosuppressive tumour microenvironment and to support T-cell expansion ${ }^{162}$, but this strategy led to notable toxicity ${ }^{163,164}$. Hence, rather than systemic cytokine administration, CAR T cells were then engineered to constitutively secrete their own cytokines ${ }^{165}$. Later, inducible armoured CAR T cells that secrete cytokines only in the tumour microenvironment ${ }^{166}$ ('safety switches') further limited the toxicity of cytokine administration while retaining their ability to restructure the tumour microenvironment at the site of action to support T-cell expansion ${ }^{167}$.

Living biological therapeutics-in particular, bacteria for correcting aberrant metabolic processes, halting cancer initiation or progression, or treating chronic inflammatory conditions ${ }^{102}-$ have also required extensive microenvironment manipulations to improve their delivery. Because the native microbiome acts as a delivery barrier, small-molecule therapeutics such as antibiotics, as well as defined biocompatible polymers such as PEG, have been repurposed as microenvironment modulators to improve the engraftment and persistence of living biological therapeutics in the gastrointestinal tract ${ }^{168}$. This highlights the benefit of using previously defined therapeutics as delivery strategies. In fact, preclinical and clinical research on cytokines for immunotherapy ${ }^{169}$ and antibiotics for infection treatment ${ }^{170}$ have enabled their repurposing as microenvironmental modulators for live-cell therapies.

Live cells are also particularly promising because of their ability to modify and interact with the microenvironment; for example, macrophages can be used to actively traffic therapeutics across the blood-brain barrier ${ }^{171,172}$. By combining genetic engineering with knowledge of microenvironmental manipulations, cell therapies can be engineered to actively sense, respond to and subsequently restructure their microenvironments (as exemplified by stimuli-responsive armoured CAR T cells). Alternatively, they can sense environmental cues to regulate gene expression and protein secretion (in the intestinal tract and at tumour sites ${ }^{173,174}$, for instance). This level of precise environmental responsiveness has been mimicked in non-biological systems for decades.

Drug delivery systems. Modifications to the drug and to its microenvironment can adjust and optimize the activity of the drug. Drug delivery systems can combine these two strategies by building an interface between the drug and its microenvironment (Table 4).

The foundational years of modern drug delivery determined that altering the rate of release of a drug in the body can shift its PK parameters, in particular its biodistribution, its half-life, total drug exposure over time and its maximum concentration in 
Table 4 | Drug delivery systems and selected clinical examples

\begin{tabular}{|c|c|c|}
\hline Class of therapeutic & System & Examples \\
\hline \multirow[t]{8}{*}{ Small molecules } & Controlled-release capsules & $\begin{array}{l}\text { Methylphenidate } \mathrm{HCl} \text { (Concerta), fexofenadine and } \\
\text { pseudoephedrine (Allegra D) }\end{array}$ \\
\hline & Controlled-release implants & Etonogestrel implant (Nexplanon), fluocinolone (Retisert) \\
\hline & Inhalable devices & $\begin{array}{l}\text { Albuterol inhalation (Proventil HFA), budesonide/formoterol } \\
\text { (Symbicort) }\end{array}$ \\
\hline & Transdermal patches & $\begin{array}{l}\text { Fentanyl transdermal system (Duragesic), transdermal nicotine } \\
\text { (NicoDerm CQ) }\end{array}$ \\
\hline & Stimuli-responsive drug release & Verteporfin for injection (Visudyne) \\
\hline & Microparticles & Risperidone (Risperdal Consta) \\
\hline & Nanoparticles & Doxorubicin (Doxil), protein-bound paclitaxel (Abraxane) \\
\hline & Targeted delivery & Ado-trastuzumab emtansine (Kadycla) \\
\hline \multirow[t]{5}{*}{ Peptides and proteins } & Controlled-release microparticle depots & $\begin{array}{l}\text { Leuprolide acetate (Lupron Depot), somatropin (Nutropin Depot; } \\
\text { withdrawn) }\end{array}$ \\
\hline & Targeted delivery systems & No clinical products yet \\
\hline & In-situ-forming polymer matrix & Leuprolide acetate (Eligard) \\
\hline & Implants & Leuprolide acetate implant (Viadur) \\
\hline & Non-invasive delivery systems & $\begin{array}{l}\text { Inhalation powder of human insulin (Afrezza), semaglutide } \\
\text { (Rybelsus) }\end{array}$ \\
\hline \multirow[t]{3}{*}{ Antibodies } & $\mathrm{ADCs}$ & $\begin{array}{l}\text { Brentuximab vedotin (Adecetris), ado-trastuzumab emtansine } \\
\text { (Kadcyla) }\end{array}$ \\
\hline & $\begin{array}{l}\text { Minimally invasive subcutaneous injections combining } \\
\text { humanized antibodies with dispersion enhancers }\end{array}$ & Trastuzumab and hyaluronidase-oysk (Herceptin Hylecta) \\
\hline & Non-invasive delivery systems & $\begin{array}{l}\text { Inhalation powder of anti-IL-13 antigen-binding fragment } \\
\text { (NCT02473939) }\end{array}$ \\
\hline \multirow[t]{4}{*}{ Nucleic acids } & Lipid-based nanoparticles & Patisiran (Onpattro), mRNA COVID-19 vaccines \\
\hline & Viral vectors & $\begin{array}{l}\text { Recombinant human p53 adenovirus (Gendicine; not approved in } \\
\text { the United States), Janssen COVID-19 vaccine }\end{array}$ \\
\hline & Polymer conjugates & Pegaptanib (Macugen) \\
\hline & Targeting-ligand conjugates & Givosiran (Givlaari) \\
\hline \multirow[t]{4}{*}{ Live-cell therapies } & $\begin{array}{l}\text { Scaffolds to sustain cell populations near the site of } \\
\text { action }\end{array}$ & Matrix-induced autologous chondrocyte implantation (MACI) \\
\hline & Microparticles and microparticle implants & SIG-001 (NCT04541628) \\
\hline & Drug-secreting therapeutic bacteria & AG019 (NCT03751007) \\
\hline & Cellular hitchhiking & PRIMEIL-15/RPTR-147 (NCT03815682) \\
\hline
\end{tabular}

serum $^{175}$. Although changing the dose, the frequency of the dose and the infusion rates can influence these parameters, the introduction of controlled-release delivery systems enabled a higher level of control ${ }^{176,177}$. These systems included hydrogels and polymeric implants based on the four mechanisms of controlled release-dissolution, diffusion, osmosis and ion exchange-and microparticles and nanoparticles, which allow for particle-surface modifications to enhance drug half-life and the targeting of particular tissues through specific interactions with the microenvironment ${ }^{19,178}$. Notably, these systems enabled the reformulation of small molecules for controlled release, such as the formulation of nifedipine (Adalat; a calcium-channel blocker), which extended the efficacy of the drug and reduced its side effects ${ }^{179}$. Polymers with controllable degradation, erosion and in situ formation formed the basis of many controlled-release systems. For example, enteric coated capsules with $\mathrm{pH}$-responsive behaviour can be used to release the drug payload in specific locations of the gastrointestinal tract ${ }^{180}$, which exemplifies a central advantage of drug delivery systems: physical protection of a drug from a hostile environment ${ }^{181}$. Controlled-release systems were applied to many formulations of small molecules. A notable example is the transdermal patch Duragesic (Fig. 2a) for the non-invasive systemic delivery of the opioid fentanyl (originally developed as an analogue of meperidine, but with improved potency and therapeutic index) with ethanol as a permeation enhancer ${ }^{122,182}$.

The foundation of controlled-release technologies developed for small molecules was essential for the development of delivery strategies for therapeutic peptides and proteins, for which short drug half-lives necessitated frequent and invasive injections. In this context, the efficacy of peptide therapeutics was bolstered by sustained-release systems - a subset of controlled-release systems that aims to maintain therapeutic drug concentrations for extended time periods. One of the earliest examples of such a system involved leuprolide acetate, formulated in microspheres (Lupron Depot) that release the therapeutic for up to 6 months ${ }^{183}$. This served as a model of sustained release that was then applied to a number of other peptide therapeutics ${ }^{184}$. Few sustained-release delivery systems for larger proteins have been approved by regulators. Examples include an injectable suspension of somatropin (Nutropin Depot), a microsphere-based sustained-release protein formulation that was approved in 1999 and subsequently withdrawn from the market, and the INFUSE Bone Graft (developed by Medtronic), an absorbable collagen sponge used for the release of bone morphogenetic protein-2 in spinal-fusion procedures ${ }^{185}$. 


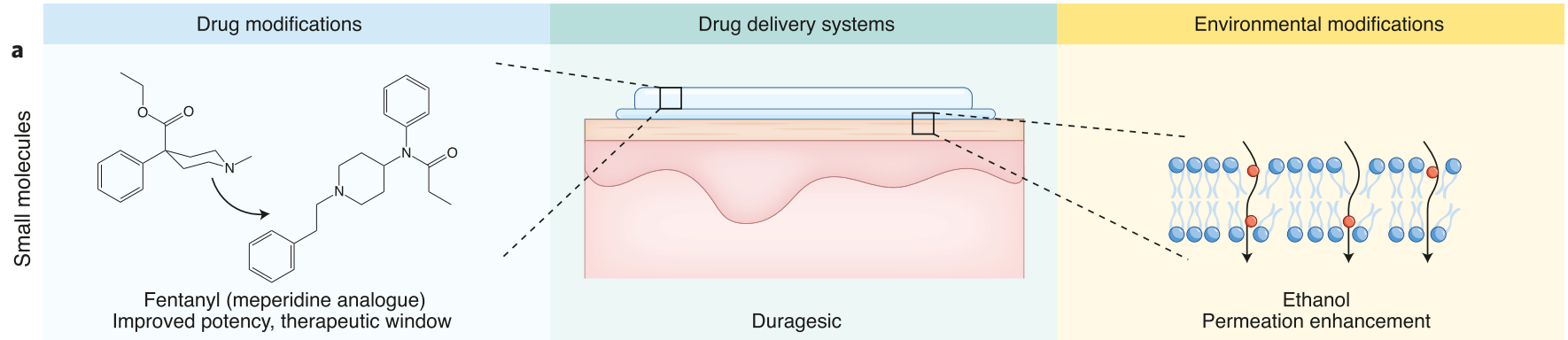

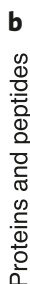
Improved potency, therapeutic window

Duragesic

Permeation enhancement
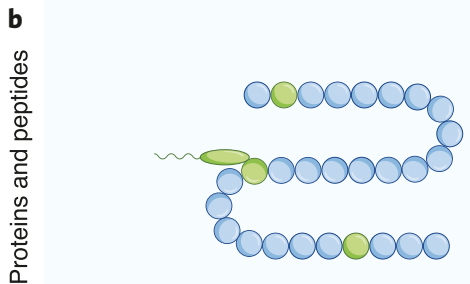

Semaglutide (amino-acid substitution) Improved stability, activity
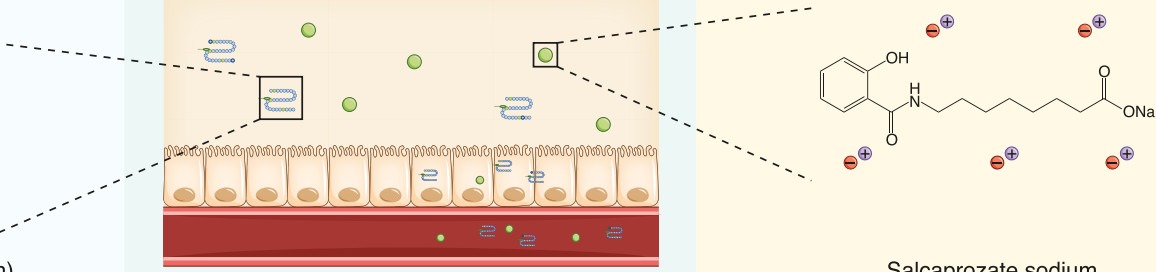

Salcaprozate sodium

Rybelsus $\mathrm{pH}$-buffering and penetration enhancement

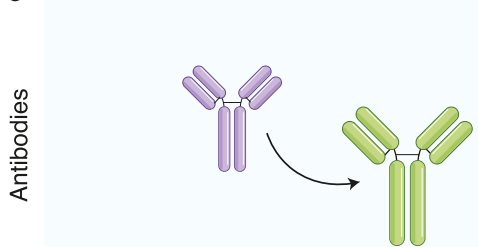

Anti-HER2 (humanized) Reduced immunogenicity

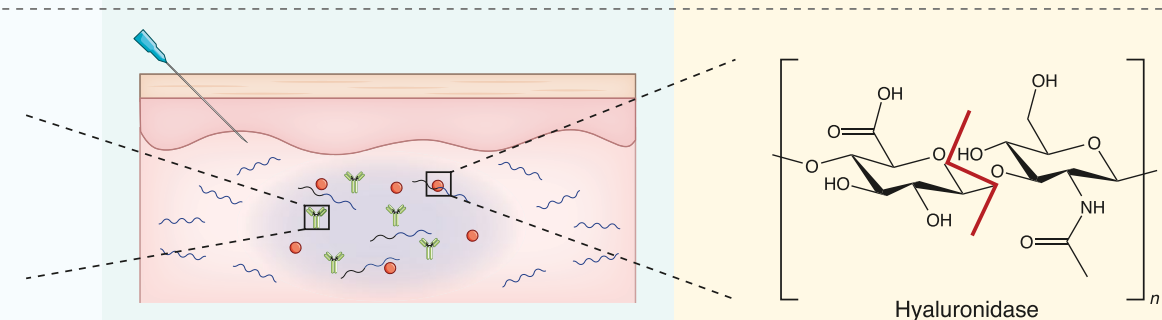
Degradation of hyaluronan

d
$\frac{0}{2}$
$\frac{0}{0}$
$\frac{0}{0}$
$\frac{0}{0}$
$\frac{3}{2}$

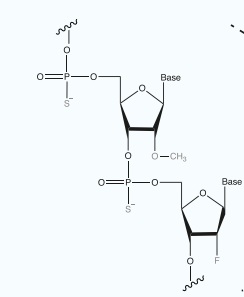

siRNA (2'-OMe, 2'-F) Improved stability, potency

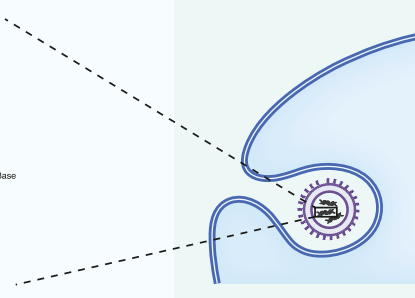

Onpattro

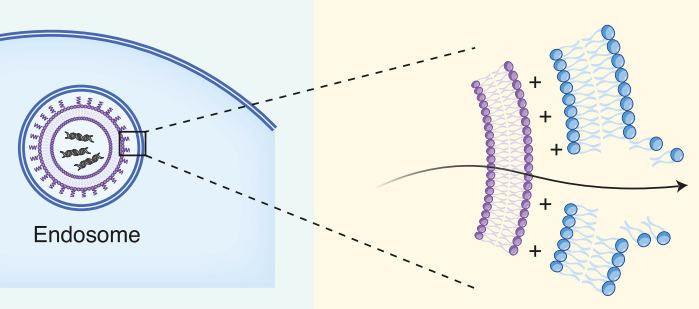

Ionizable cationic lipids Endosomal escape

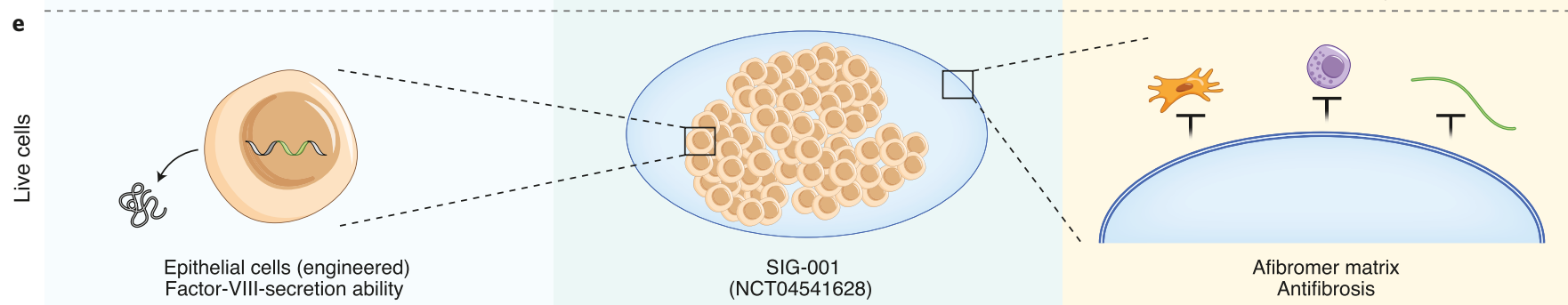

Fig. 2 | Delivery systems integrating drug modifications and environmental modifications. The integration of drug modifications (left) and environmental modifications (right) into drug delivery systems (middle) has been applied across all classes of therapeutic. Shown are clinical examples of multifunctional delivery systems for all five classes of therapeutic. a, A small-molecule analogue with a permeation enhancer (trade name, Duragesic). b, An amino-acidmodified peptide with a permeation enhancer (Rybelsus). c, A humanized mAb with hyaluronidase for subcutaneous restructuring (Herceptin Hylecta). d, A chemically modified siRNA with ionizable lipids for endosomal escape (Onpattro). e, A genetically engineered cell for the secretion of factor $\mathrm{VIII}$ in an immune-modulating polymer matrix (SIG-001).

Drug modifications have been essential for the development of non-invasive controlled-release delivery systems for protein and peptide therapeutics. Peptides and proteins have been rationally designed to control their solubility (this is the case for insulin) and to improve their stability (as with desmopressin) and therefore their PKs. A notable example is the GLP-1 analogue semaglutide, which exhibits better enzymatic stability than other clinically approved GLP-1 agonists ${ }^{46}$. Rybelsus combines the stability advantages of semaglutide (a modified peptide with amino acid substitutions and a carbon chain addition) with environmental modifications that buffer the local $\mathrm{pH}$ to facilitate safe transport of the drug through stomach acids and to enhance its permeation across the epithelium ${ }^{46}$ 
(Fig. 2b). In some cases, a delivery system can reduce or eliminate the need for environmental modulators altogether, as is the case for a vesicular system (from Diasome Pharmaceuticals) that shields orally administered insulin from enzymes during transit ${ }^{186}$.

For antibody therapeutics, dispersion enhancers have enabled the controlled release of antibodies following subcutaneous injections. One such system, a combination of trastuzumab and hyaluronidase-oysk (Herceptin Hylecta), delivers the humanized antibody trastuzumab (Herceptin) using hyaluronidases to facilitate its enhanced dispersion in the subcutaneous space via hyaluronan degradation, thus allowing for greater injection volumes and for subsequent systemic absorption ${ }^{70,187}$ (Fig. 2c). By enabling subcutaneous injection in lieu of intravenous infusions, this system improves patient acceptance and convenience. Remarkably, six approved ADCs (Mylotarg, Adcetris, Besponsa, Polivy, Padcev and Trodelvy ${ }^{75,188}$ were developed with targeting antibodies that do not show clinical efficacy on their own ${ }^{76}$. Still, a few ADCs use mAbs with validated therapeutic efficacy (this is the case of Kadcyla, which uses Herceptin), illustrating that they can act as multifunctional therapeutics (that is, an ADC can combine two anticancer drugs as a single treatment ${ }^{189}$ ).

Nucleic acids have greatly benefitted from drug delivery systems. This is exemplified by the recently approved siRNA therapeutic Onpattro, a lipid-based nanoparticle with chemically modified siRNA for cell targeting, uptake and endosomal escape (Fig. 2d). Early work on cationic liposomes and lipid-nucleic-acid complexes showed their utility for nonviral gene therapy. They enabled the encapsulation of negatively charged nucleic acids with high efficiency, and their surface charge improved active cellular uptake and endosomal escape in vivo ${ }^{190-193}$. However, toxicity, complement activation and poor biodistribution led to the development of lipid-based delivery systems specifically for siRNA, including lipid nanoparticles that incorporated PEGylated, neutral and ionizable cationic lipids as stable carriers ${ }^{194-196}$. The inclusion of an ionizable cationic lipid was particularly important, as it retained the advantages of liposomes, including high loading efficiencies and endosomal escape, and improved siRNA delivery efficiency by reducing toxicity and improving biodistribution ${ }^{197}$. Lipid nanoparticles are now being investigated more broadly for the delivery of nucleic acids, including mRNA $^{198}$. In fact, for the mRNA-based COVID-19 vaccines, the use of lipid nanoparticles and nucleoside modifications improve the stability and translation efficacy of the delivered nucleic acid (Box 2). Generally, delivery systems can improve the stability, targeting and PKs of drugs, and package modified therapeutics with microenvironmental modifiers to better control the interactions of drugs with molecules, cells and tissues in the human body.

New and repurposed delivery systems will be essential for the clinical translation of cell therapies (Fig. 2), particularly those that combine cell modifications (such as genetic engineering, surface conjugation or stimulus exposure for antigen presentation or cellular differentiation) with microenvironmental modifications (such as the secretion, presentation or co-delivery of cytokines, antibodies or small molecules). A number of existing drug delivery systems have been optimized for the protection, targeting and activation of cell therapies. In one example, induced insulin-secreting $\beta$-cells to treat type- 1 diabetes were encapsulated in polymer implants to extend the viability of the cells and the maintenance of blood glucose levels ${ }^{117}$. By using chemically modified alginate, the implant minimizes the formation of a fibrotic capsule (the natural response in the local microenvironment) ${ }^{199}$. This leverages knowledge accumulated through decades of research across all generations of therapeutics. The chemically modified alginate polymer was selected for its antifibrotic characteristics by using high-throughput small-molecule screening, a technique originally developed for small molecules ${ }^{199,200}$, and the use of alginate dates back to the first alginate-based clinical system (Emdogain) for protein delivery $^{201}$. The functional human pancreatic $\beta$-cells also rely on a drug-modification strategy used in stem cell differentiation to turn haematopoietic stem and progenitor cells into insulin-secreting $\operatorname{depots}^{117,202}$. This example also highlights how the combination of drug modifications (differentiated cells for secretion of biologics) with microenvironment modifications (immune-modulating alginate) can be used to optimize delivery systems for live cells. Similar microencapsulation systems are being developed for phase I human trials for the treatment of haemophilia (SIG-001) by protecting and delivering epithelial cells genetically engineered to secrete factor VIII $^{203}$ (Fig. 2e). Furthermore, alginate-based polymer implants have been used preclinically for the sustained release of engineered CAR T cells directly at the tumour site and to simultaneously support their in vivo expansion ${ }^{204}$. This system leverages knowledge of the tumour microenvironment and its immune interactions to develop microparticles that both activate CAR T cells by mimicking antigen presentation and to restructure the tumour microenvironment to support CAR T-cell growth through the release of soluble cytokines. This shows the utility of integrating the three primary delivery strategies: genetically modified CAR T cells for therapeutic function, microenvironment-modulating particles to support those functions and the packaging of them in a controlled-release delivery system for the mediation of cell-environment interactions. This example holds similarities with the cellular-hitchhiking strategy in PRIME ${ }^{\mathrm{IL}-15} / \mathrm{RPTR}-147$, which combines a live-cell therapy with environmental modulators to improve T-cell persistence and expansion $^{151}$.

As new cell therapies are introduced, new biomaterials synthesized and characterized and immunomodulatory mechanisms better defined, we expect delivery systems developed for cell therapies to also benefit earlier classes of therapeutic. In particular, challenges related to immune activation following the transplantation of live tissues or cells have led to advances in immune-modulatory biomaterials that can control host tolerance ${ }^{205}$. This is apparent in the example highlighted earlier in this section: the requirement for sustained $\beta$-cell action led to the development of fibrosis-resistant biomaterials (Afibrotek) that can now be used with any class of therapeutic. However, the manufacturing and scale-up of cell therapies faces considerable challenges. Existing good manufacturing practices and quality-by-design principles are difficult to apply to live-cell therapies owing to their sensitivity to environmental changes, which poses challenges in the maintenance of cell viability and sterility as well as substantially increased $\operatorname{costs}^{206}$. One key outstanding challenge for cell therapies is the identification of critical attributes that can be used to ensure therapeutic quality and function following production ${ }^{113}$. Efforts to improve the safety of allogeneic cell therapies, which require simpler manufacturing practices ${ }^{207}$, and technologies that streamline ex vivo cell modification show promise for addressing these challenges. For example, microfluidic-based systems (developed by SQZ Biotech) are being used in a clinical trial to rapidly (less than 24hours) engineer immune cell therapies ex vivo $^{208}$ (NCT04084951). Moreover, in situ cell modification strategies that aim to redirect host cells as live therapies may reduce or eliminate the need for ex vivo cell manufacturing in specific instances ${ }^{209}$. For example, targeted nucleic acid carriers can engineer therapeutic host cells (such as CAR T cells ${ }^{146}$, biologic-secreting depots $^{149}$ and live-cell vaccines ${ }^{210}$ ), immune-modulation and microenvironmental modulation can induce therapeutic cell-mediated immune responses ${ }^{114,211,212}$, and biomaterials can be used as artificial antigen-presenting cells for host immune-cell priming ${ }^{204,213}$.

\section{Outlook}

Drug delivery has evolved alongside generations of therapeuticsfrom small molecules to proteins and peptides, to nucleic acids and, most recently, to live-cell therapies. Delivery challenges for 
each of these classes of therapeutic (Table 1) have been addressed through drug modifications (Table 2) and microenvironmental modifications (Table 3). In fact, multifunctional delivery systems have improved delivery for all classes of therapeutic (Fig. 1), with delivery systems with superior control over drug action (Table 4) often combining drug modifications and environmental modifications (Fig. 2).

During the evolution of drug delivery, established delivery approaches have been applied to improve the translation of emerging therapeutic modalities, as exemplified by the application of controlled-release and sustained-release systems (originally developed for small molecules) across the therapeutic spectrum. Conversely, delivery strategies and technologies developed for new therapeutic modalities have then been adapted to improve the delivery of older therapeutics. For example, PEG conjugation was applied to proteins before it was used to improve the delivery of small molecules (Box 1), and high-throughput screening techniques first developed to optimize small-molecule therapies have helped to identify microenvironment-modulating materials for live-cell delivery (as exemplified by the clinical use of immune-modulating polymers for SIG-001, an extended cell therapy depot that secretes human factor VIII for the treatment of haemophilia A). Environmental modifiers have also been repurposed across classes of therapeutic, including cytokines for the modification of the tumour microenvironment in cell-based immunotherapies, antibiotics for the engraftment of living biological therapeutics and chemically synthesized cell-penetrating peptides for improving the intracellular delivery of nucleic acids and small molecules ${ }^{214}$. Moreover, advancements made in the context of one class of therapeutic have facilitated the clinical translation of therapeutics belonging to other classes. For example, therapeutic antibodies have been used as drug modifiers for small molecules (in the form of ADCs). These leverage the specificity of the antibody to facilitate site-specific delivery and have enabled the clinical translation of cytotoxic compounds with unacceptably high levels of toxicity (one example is monomethyl auristatin E, a synthetic antineoplastic small molecule).

An analysis of the existing landscape of therapeutics and delivery approaches (drug modifications and environmental modifications) suggests that there are three general outstanding challenges: targeted delivery with single-cell or cell-compartment resolution, overcoming biological barriers that limit the delivery of complex therapeutic molecules and the development of drug delivery systems that rapidly secrete biomolecules in specific tissues at specific times and concentrations in response to environmental cues. Although these challenges will not prevent the implementation of the majority of therapeutics, we believe that cell therapies can address them simultaneously and lead to effective single-dose drug delivery systems. Indeed, cell therapies can provide a sustained source of complex biologics, negotiate biological barriers and respond to host cues in ways that mimic natural biological processes. As such, cell therapies can act both as a dynamic delivery system and as a therapeutic. Cell therapies are therefore particularly suited for the treatment or the management of rare blood disorders (such as haemophilia and sickle cell disease), poorly responsive cancers and metabolic genetic disorders. And by virtue of them mimicking key biological processes (for example, host-responsive insulin secretion), advanced cell therapies may reduce dosing frequency and the need or number of certain medical interventions. If history is a guide, cell therapies will take advantage of established approaches to modify drugs and their microenvironment to control drug action, efficacy and toxicity; conversely, specific improvements to the approaches will benefit the other classes of therapeutic.

Received: 22 June 2020; Accepted: 11 February 2021; Published online: 1 April 2021

\section{References}

1. Chien, Y. Novel Drug Delivery Systems (CRC Press, 1991).

2. Langer, R. Drug delivery and targeting. Nature 392, 5-10 (1998)

3. Langer, R. New methods of drug delivery. Science 249, 1527-1533 (1990).

4. Allen, T. M. \& Cullis, P. R. Drug delivery systems: entering the mainstream. Science 303, 1818-1822 (2004)

5. Gidal, B. E. et al. Gabapentin bioavailability: effect of dose and frequency of administration in adult patients with epilepsy. Epilepsy Res. 31, 91-99 (1998).

6. Serajuddin, A. T. Solid dispersion of poorly water-soluble drugs: early promises, subsequent problems, and recent breakthroughs. J. Pharm. Sci. 88, 1058-1066 (1999).

7. Schmidt, B. et al. A natural history of botanical therapeutics. Metabolism 57, S3-S9 (2008).

8. Washington, N., Washington, C. \& Wilson, C. Physiological Pharmaceutics: Barriers to Drug Absorption (CRC Press, 2000).

9. Savjani, K. T., Gajjar, A. K. \& Savjani, J. K. Drug solubility: importance and enhancement techniques. ISRN Pharm. 2012, 195727 (2012).

10. Kalepu, S. \& Nekkanti, V. Insoluble drug delivery strategies: review of recent advances and business prospects. Acta Pharm. Sinica B 5, 442-453 (2015).

11. Sharma, P. C., Jain, A., Jain, S., Pahwa, R. \& Yar, M. S. Ciprofloxacin: review on developments in synthetic, analytical, and medicinal aspects. J. Enzym. Inhib. Med. Chem. 25, 577-589 (2010)

12. Beaumont, K., Webster, R., Gardner, I. \& Dack, K. Design of ester prodrugs to enhance oral absorption of poorly permeable compounds: challenges to the discovery scientist. Curr. Drug Metab. 4, 461-485 (2003).

13. Kempf, D. J. et al. Discovery of ritonavir, a potent inhibitor of HIV protease with high oral bioavailability and clinical efficacy. J. Med. Chem. 41, 602-617 (1998).

14. Nelson, E. Kinetics of drug absorption, distribution, metabolism, and excretion. J. Pharm. Sci. 50, 181-192 (1961).

15. Teorell, T. Kinetics of distribution of substances administered to the body, I: the extravascular modes of administration. Arch. Int. Pharmacodyn. Ther. 57, 205-225 (1937).

16. Dost, F. H. Der Blutspiegel: Kinetik der Konzentrationsabläufe in der Kreislaufflüssigkeit (Georg Thieme, 1953).

17. Kubitza, D., Becka, M., Wensing, G., Voith, B. \& Zuehlsdorf, M. Safety, pharmacodynamics, and pharmacokinetics of BAY 59-7939-an oral, direct factor Xa inhibitor-after multiple dosing in healthy male subjects. Eur. J. Clin. Pharmacol. 61, 873-880 (2005).

18. Chien, S. C. et al. Pharmacokinetic profile of levofloxacin following once-daily 500-milligram oral or intravenous doses. Antimicrob. Agents Chemother. 41, 2256-2260 (1997).

19. Park, K. Controlled drug delivery systems: past forward and future back. J. Control. Release 190, 3-8 (2014).

20. Keraliya, R. A. et al. Osmotic drug delivery system as a part of modified release dosage form. ISRN Pharm. 2012, 528079 (2012).

21. Prausnitz, M. R. \& Langer, R. Transdermal drug delivery. Nat. Biotechnol. 26, 1261-1268 (2008).

22. Anselmo, A. C. \& Mitragotri, S. Nanoparticles in the clinic. Bioeng. Transl. Med. 1, 10-29 (2016).

23. Anselmo, A. C. \& Mitragotri, S. Nanoparticles in the clinic: an update. Bioeng. Transl. Med. 4, e10143 (2019).

24. Albanese, A., Tang, P. S. \& Chan, W. C. W. The effect of nanoparticle size, shape, and surface chemistry on biological systems. Annu. Rev. Biomed. Eng. 14, 1-16 (2012)

25. Champion, J. A., Katare, Y. K. \& Mitragotri, S. Particle shape: a new design parameter for micro- and nanoscale drug delivery carriers. J. Control. Release 121, 3-9 (2007).

26. Champion, J. A., Walker, A. \& Mitragotri, S. Role of particle size in phagocytosis of polymeric microspheres. Pharm. Res. 25, 1815-1821 (2008)

27. Win, K. Y. \& Feng, S.-S. Effects of particle size and surface coating on cellular uptake of polymeric nanoparticles for oral delivery of anticancer drugs. Biomaterials 26, 2713-2722 (2005).

28. Papahadjopoulos, D. et al. Sterically stabilized liposomes: improvements in pharmacokinetics and antitumor therapeutic efficacy. Proc. Natl Acad. Sci. USA 88, 11460-11464 (1991).

29. Barenholz, Y. Doxil-the first FDA-approved nano-drug: lessons learned. J. Control. Release 160, 117-134 (2012).

30. Hopkins, A. L. \& Groom, C. R. The druggable genome. Nat. Rev. Drug Discov. 1, 727-730 (2002).

31. Rask-Andersen, M., Masuram, S. \& Schioth, H. B. The druggable genome: evaluation of drug targets in clinical trials suggests major shifts in molecular class and indication. Annu. Rev. Pharmacol. Toxicol. 54, 9-26 (2014).

32. Lau, J. L. \& Dunn, M. K. Therapeutic peptides: historical perspectives, current development trends, and future directions. Bioorg. Med. Chem. 26, 2700-2707 (2018). 
33. Bruno, B. J., Miller, G. D. \& Lim, C. S. Basics and recent advances in peptide and protein drug delivery. Ther. Deliv. 4, 1443-1467 (2013).

34. Craik, D. J., Fairlie, D. P., Liras, S. \& Price, D. The future of peptide-based Drugs Chem. Biol. Drug Des. 81, 136-147 (2013).

35. Putney, S. D. \& Burke, P. A. Improving protein therapeutics with sustained-release formulations. Nat. Biotechnol. 16, 153-157 (1998).

36. Pisal, D. S., Kosloski, M. P. \& Balu-Iyer, S. V. Delivery of therapeutic proteins. J. Pharm. Sci. 99, 2557-2575 (2010).

37. Schuster, J. et al. In vivo stability of therapeutic proteins. Pharm. Res. 37, 23 (2020).

38. Baker, M. P., Reynolds, H. M., Lumicisi, B. \& Bryson, C. J. Immunogenicity of protein therapeutics: the key causes, consequences and challenges. Self Nonself 1, 314-322 (2010).

39. Jawa, V. et al. T-cell dependent immunogenicity of protein therapeutics: preclinical assessment and mitigation. Clin. Immunol. 149, 534-555 (2013).

40. Rosenberg, A. S. \& Sauna, Z. E. Immunogenicity assessment during the development of protein therapeutics. J. Pharm. Pharmacol. 70, 584-594 (2018).

41. Di, L. Strategic approaches to optimizing peptide ADME properties. AAPS J. 17, 134-143 (2015).

42. Ovadia, O. et al. Improvement of drug-like properties of peptides: the somatostatin paradigm. Expert Opin. Drug Discov. 5, 655-671 (2010).

43. Jevsevar, S., Kunstelj, M. \& Porekar, V. G. PEGylation of therapeutic proteins. Biotechnol. J. 5, 113-128 (2010).

44. Brown, T. D., Whitehead, K. A. \& Mitragotri, S. Materials for oral delivery of proteins and peptides. Nat. Rev. Mater. 5, 127-148 (2019).

45. Drucker, D. J. Advances in oral peptide therapeutics. Nat. Rev. Drug Discov. 19, 277-289 (2020).

46. Suzuki, R., Brown, G. A., Christopher, J. A., Scully, C. C. G. \& Congreve, M. Recent developments in therapeutic peptides for the glucagon-like peptide 1 and 2 receptors. J. Med. Chem. 63, 905-927 (2020).

47. Anselmo, A. C., Gokarn, Y. \& Mitragotri, S. Non-invasive delivery strategies for biologics. Nat. Rev. Drug Discov. 18, 19-40 (2019).

48. Morales, J. O. et al. Challenges and future prospects for the delivery of biologics: oral mucosal, pulmonary, and transdermal routes. AAPS J. 19, 652-668 (2017).

49. Ritschel, W. Microemulsion technology in the reformulation of cyclosporine: the reason behind the pharmacokinetic properties of Neoral Clin. Transplant. 10, 364-373 (1996).

50. Pfutzner, A., Mann, A. E. \& Steiner, S. S. Technosphere/insulin-a new approach for effective delivery of human insulin via the pulmonary route. Diabetes Technol. Ther. 4, 589-594 (2002)

51. Dlugi, A. M., Miller, J. D., Knittle, J. \& Group, L. S. Lupron depot (leuprolide acetate for depot suspension) in the treatment of endometriosis: a randomized, placebo-controlled, double-blind study. Fertil. Steril. 54, 419-427 (1990).

52. Mura, S., Nicolas, J. \& Couvreur, P. Stimuli-responsive nanocarriers for drug delivery. Nat. Mater. 12, 991-1003 (2013).

53. Jain, D., Raturi, R., Jain, V., Bansal, P. \& Singh, R. Recent technologies in pulsatile drug delivery systems. Biomatter 1, 57-65 (2011).

54. $\mathrm{Yu}, \mathrm{J}$. et al. Microneedle-array patches loaded with hypoxia-sensitive vesicles provide fast glucose-responsive insulin delivery. Proc. Natl Acad. Sci. USA 112, 8260-8265 (2015).

55. Lu, R.-M. et al. Development of therapeutic antibodies for the treatment of diseases. J. Biomed. Sci. 27, 1 (2020).

56. Chames, P., Van Regenmortel, M., Weiss, E. \& Baty, D. Therapeutic antibodies: successes, limitations and hopes for the future. Br. J. Pharmacol. 157, 220-233 (2009).

57. Shih, T. \& Lindley, C. Bevacizumab: an angiogenesis inhibitor for the treatment of solid malignancies. Clin. Ther. 28, 1779-1802 (2006).

58. Smith, M. R. Rituximab (monoclonal anti-CD20 antibody): mechanisms of action and resistance. Oncogene 22, 7359-7368 (2003).

59. Aarden, L., Ruuls, S. R. \& Wolbink, G. Immunogenicity of anti-tumor necrosis factor antibodies-toward improved methods of anti-antibody measurement. Curr. Opin. Immunol. 20, 431-435 (2008).

60. Baert, F. et al. Influence of immunogenicity on the long-term efficacy of infliximab in Crohn's disease. N. Engl. J. Med. 348, 601-608 (2003)

61. Atzeni, F. et al. Immunogenicity and autoimmunity during anti-TNF therapy. Autoimmun. Rev. 12, 703-708 (2013).

62. Sgro, C. Side-effects of a monoclonal antibody, muromonab CD3/ orthoclone OKT3: bibliographic review. Toxicology 105, 23-29 (1995).

63. Reichert, J. M. Marketed therapeutic antibodies compendium. mAbs 4, 413-415 (2012).

64. Suzuki, M., Kato, C. \& Kato, A. Therapeutic antibodies: their mechanisms of action and the pathological findings they induce in toxicity studies. $J$. Toxicol. Pathol. 28, 133-139 (2015).

65. Jones, P. T., Dear, P. H., Foote, J., Neuberger, M. S. \& Winter, G. Replacing the complementarity-determining regions in a human antibody with those from a mouse. Nature 321, 522-525 (1986)
66. McCafferty, J., Griffiths, A. D., Winter, G. \& Chiswell, D. J. Phage antibodies: filamentous phage displaying antibody variable domains. Nature 348, 552-554 (1990).

67. Bradbury, A. R., Sidhu, S., Dubel, S. \& McCafferty, J. Beyond natural antibodies: the power of in vitro display technologies. Nat. Biotechnol. 29, 245-254 (2011).

68. Chapman, A. P. PEGylated antibodies and antibody fragments for improved therapy: a review. Adv. Drug Deliv. Rev. 54, 531-545 (2002).

69. Ryman, J. T. \& Meibohm, B. Pharmacokinetics of monoclonal antibodies. CPT Pharmacometrics Syst. Pharm. 6, 576-588 (2017).

70. Frost, G. I. Recombinant human hyaluronidase (rHuPH20): an enabling platform for subcutaneous drug and fluid administration. Expert Opin. Drug Deliv. 4, 427-440 (2007).

71. Sugahara, K. N. et al. Coadministration of a tumor-penetrating peptide enhances the efficacy of cancer drugs. Science 328, 1031-1035 (2010).

72. Gabrilovich, D. I., Ishida, T., Nadaf, S., Ohm, J. E. \& Carbone, D. P. Antibodies to vascular endothelial growth factor enhance the efficacy of cancer immunotherapy by improving endogenous dendritic cell function. Clin. Cancer Res. 5, 2963-2970 (1999).

73. Wei, S. C. et al. Distinct cellular mechanisms underlie anti-CTLA-4 and anti-PD-1 checkpoint blockade. Cell 170, 1120-1133.e17 (2017).

74. Meadows, K. L. \& Hurwitz, H. I. Anti-VEGF therapies in the clinic Cold Spring Harb. Perspect. Med. 2, a006577 (2012).

75. Alley, S. C., Okeley, N. M. \& Senter, P. D. Antibody-drug conjugates: targeted drug delivery for cancer. Curr. Opin. Chem. Biol. 14, 529-537 (2010).

76. Beck, A., Goetsch, L., Dumontet, C. \& Corvaïa, N. Strategies and challenges for the next generation of antibody-drug conjugates. Nat. Rev. Drug Discov. 16, 315-337 (2017).

77. Opalinska, J. B. \& Gewirtz, A. M. Nucleic-acid therapeutics: basic principles and recent applications. Nat. Rev. Drug Discov. 1, 503-514 (2002).

78. Mali, P. et al. RNA-guided human genome engineering via Cas9. Science 339, 823-826 (2013).

79. de Smet, M. D., Meenken, C. \& van den Horn, G. J. Fomivirsen-a phosphorothioate oligonucleotide for the treatment of CMV retinitis. Ocul. Immunol. Inflamm. 7, 189-198 (1999).

80. Rinaldi, C. \& Wood, M. J. A. Antisense oligonucleotides: the next frontier for treatment of neurological disorders. Nat. Rev. Neurol. 14, 9-21 (2018).

81. Kaczmarek, J. C., Kowalski, P. S. \& Anderson, D. G. Advances in the delivery of RNA therapeutics: from concept to clinical reality. Genome Med. 9, 60 (2017).

82. Van Hoecke, L. \& Roose, K. How mRNA therapeutics are entering the monoclonal antibody field. J. Transl. Med. 17, 54 (2019).

83. Behlke, M. A. Chemical modification of siRNAs for in vivo use Oligonucleotides 18, 305-320 (2008).

84. Kormann, M. S. et al. Expression of therapeutic proteins after delivery of chemically modified mRNA in mice. Nat. Biotechnol. 29, 154-157 (2011).

85. Khvorova, A. \& Watts, J. K. The chemical evolution of oligonucleotide therapies of clinical utility. Nat. Biotechnol. 35, 238-248 (2017).

86. Endoh, T. \& Ohtsuki, T. Cellular siRNA delivery using cell-penetrating peptides modified for endosomal escape. Adv. Drug Deliv. Rev. 61, 704-709 (2009).

87. Liang, W. \& Lam, J. K. W. in Molecular Regulation of Endocytosis (ed. Ceresa, B) 429-456 (IntechOpen, 2012).

88. Whitehead, K. A., Langer, R. \& Anderson, D. G. Knocking down barriers advances in siRNA delivery. Nat. Rev. Drug Discov. 8, 129-138 (2009).

89. Garber, K. Alnylam launches era of RNAi drugs. Nat. Biotechnol. 36 , 777-778 (2018).

90. Scott, L. J. Givosiran: first approval. Drugs 80, 335-339 (2020).

91. Scherphof, G. L., Dijkstra, J., Spanjer, H. H., Derksen, J. T. \& Roerdink, F. H Uptake and intracellular processing of targeted and nontargeted liposomes by rat Kupffer cells in vivo and in vitro. Ann. NY Acad. Sci. 446, 368-384 (1985).

92. Wu, G. Y. \& Wu, C. H. Receptor-mediated in vitro gene transformation by a soluble DNA carrier system. J. Biol. Chem. 262, 4429-4432 (1987).

93. Baenziger, J. U. \& Fiete, D. Galactose and $N$-acetylgalactosaminespecific endocytosis of glycopeptides by isolated rat hepatocytes. Cell 22, 611-620 (1980).

94. Nair, J. K. et al. Multivalent $\mathrm{N}$-acetylgalactosamine-conjugated siRNA localizes in hepatocytes and elicits robust RNAi-mediated gene silencing. J. Am. Chem. Soc. 136, 16958-16961 (2014).

95. Allen, T. M. \& Cullis, P. R. Liposomal drug delivery systems: from concept to clinical applications. Adv. Drug Deliv. Rev. 65, 36-48 (2013).

96. Moghimi, S. M., Hunter, A. C. \& Murray, J. C. Long-circulating and target-specific nanoparticles: theory to practice. Pharm. Rev. 53, 283-318 (2001).

97. Polack, F. P. et al. Safety and efficacy of the BNT162b2 mRNA Covid-19 vaccine. N. Engl. J. Med. 383, 2603-2615 (2020). 
98. Baden, L. R. et al. Efficacy and safety of the mRNA-1273 SARS-CoV-2 vaccine. N. Engl. J. Med. https://doi.org/10.1056/NEJMoa2035389 (2020).

99. Frenette, P. S., Pinho, S., Lucas, D. \& Scheiermann, C. Mesenchymal stem cell: keystone of the hematopoietic stem cell niche and a stepping-stone for regenerative medicine. Annu. Rev. Immunol. 31, 285-316 (2013).

100. Palucka, K. \& Banchereau, J. Dendritic-cell-based therapeutic cancer vaccines. Immunity 39, 38-48 (2013).

101. June, C. H., O’Connor, R. S., Kawalekar, O. U., Ghassemi, S. \& Milone, M. C. CAR T cell immunotherapy for human cancer. Science 359, 1361-1365 (2018).

102. Vargason, A. M. \& Anselmo, A. C. Clinical translation of microbe-based therapies: current clinical landscape and preclinical outlook. Bioeng. Transl. Med. 3, 124-137 (2018).

103. Prasad, V. Tisagenlecleucel-the first approved CAR-T-cell therapy: implications for payers and policy makers. Nat. Rev. Clin. Oncol. 15, 11-12 (2018).

104. Jackson, H. J., Rafiq, S. \& Brentjens, R. J. Driving CAR T-cells forward. Nat. Rev. Clin. Oncol. 13, 370-383 (2016).

105. Cheever, M. A. \& Higano, C. S. PROVENGE (Sipuleucel-T) in prostate cancer: the first FDA-approved therapeutic cancer vaccine. Clin. Cancer Res. 17, 3520-3526 (2011).

106. Office of Tissues and Advanced Therapies. Approved Cellular and Gene Therapy Products https://www.fda.gov/vaccines-blood-biologics/ cellular-gene-therapy-products/approved-cellular-and-gene-therapy-products (US Food and Drug Adminstration, 2019).

107. Riglar, D. T. \& Silver, P. A. Engineering bacteria for diagnostic and therapeutic applications. Nat. Rev. Microbiol. 16, 214-225 (2018).

108. Volkman, R. \& Offen, D. Concise review: mesenchymal stem cells in neurodegenerative diseases. Stem Cells 35, 1867-1880 (2017).

109. Newick, K., O’Brien, S., Moon, E. \& Albelda, S. M. CAR T cell therapy for solid tumors. Annu. Rev. Med. 68, 139-152 (2017).

110. Gargett, T. et al. GD2-specific CAR T cells undergo potent activation and deletion following antigen encounter but can be protected from activation-induced cell death by PD-1 blockade. Mol. Ther. 24, 1135-1149 (2016).

111. Fraietta, J. A. et al. Determinants of response and resistance to CD19 chimeric antigen receptor (CAR) T cell therapy of chronic lymphocytic leukemia. Nat. Med. 24, 563-571 (2018).

112. Hourd, P., Ginty, P., Chandra, A. \& Williams, D. J. Manufacturing models permitting roll out/scale out of clinically led autologous cell therapies: regulatory and scientific challenges for comparability. Cytotherapy 16, 1033-1047 (2014).

113. Levine, B. L., Miskin, J., Wonnacott, K. \& Keir, C. Global manufacturing of CAR T cell therapy. Mol. Ther. Methods Clin. Dev. 4, 92-101 (2017).

114. Liu, Y., Guo, J. \& Huang, L. Modulation of tumor microenvironment for immunotherapy: focus on nanomaterial-based strategies. Theranostics 10, 3099-3117 (2020).

115. Jarosławski, S. \& Toumi, M. Sipuleucel-T (Provenge)-autopsy of an innovative paradigm change in cancer treatment: why a single-product biotech company failed to capitalize on its breakthrough invention. BioDrugs 29, 301-307 (2015).

116. Abou-El-Enein, M., Elsanhoury, A. \& Reinke, P. Overcoming challenges facing advanced therapies in the EU market. Cell Stem Cell 19, 293-297 (2016).

117. Vegas, A. J. et al. Long-term glycemic control using polymer-encapsulated human stem cell-derived beta cells in immune-competent mice. Nat. Med. 22, 306-311 (2016)

118. Tang, L. et al. Enhancing T cell therapy through TCR-signaling-responsive nanoparticle drug delivery. Nat. Biotechnol. 36, 707-716 (2018).

119. Stephan, M. T., Moon, J. J., Um, S. H., Bershteyn, A. \& Irvine, D. J. Therapeutic cell engineering with surface-conjugated synthetic nanoparticles. Nat. Med. 16, 1035-1041 (2010).

120. Kauer, T. M., Figueiredo, J.-L., Hingtgen, S. \& Shah, K. Encapsulated therapeutic stem cells implanted in the tumor resection cavity induce cell death in gliomas. Nat. Neurosci. 15, 197-204 (2012).

121. Gordh, T. Xylocain-a new local analgesic. Anaesthesia 4, 4-9 (1949).

122. Stanley, T. H. The history and development of the fentanyl series. J. Pain Symptom Manag. 7, S3-S7 (1992)

123. Tishler, M. in Molecular Modification in Drug Design Vol. 45 (ed. Schueler, F. W.) Ch. 1 (American Chemical Society, 1964)

124. Pereira, D. A. \& Williams, J. A. Origin and evolution of high throughput screening. Br. J. Pharmacol. 152, 53-61 (2007).

125. Lipinski, C. A., Lombardo, F., Dominy, B. W. \& Feeney, P. J. Experimental and computational approaches to estimate solubility and permeability in drug discovery and development settings. Adv. Drug Deliv. Rev. 23, 3-25 (1997).

126. Hewitt, W. M. et al. Cell-permeable cyclic peptides from synthetic libraries inspired by natural products. J. Am. Chem. Soc. 137, 715-721 (2015).
127. Heinis, C. \& Winter, G. Encoded libraries of chemically modified peptides. Curr. Opin. Chem. Biol. 26, 89-98 (2015).

128. Harris, J. M., Martin, N. E. \& Modi, M. Pegylation: a novel process for modifying pharmacokinetics. Clin. Pharmacokinet. 40, 539-551 (2001).

129. Dunn, C. J., Plosker, G. L., Keating, G. M., McKeage, K. \& Scott, L. J. Insulin glargine. Drugs 63, 1743-1778 (2003).

130. Jonassen, I. et al. Design of the novel protraction mechanism of insulin degludec, an ultra-long-acting basal insulin. Pharm. Res. 29, 2104-2114 (2012).

131. Birkeland, K. I. et al. Insulin degludec in type 1 diabetes. Diabetes Care 34, 661-665 (2011).

132. Nelson, A. L., Dhimolea, E. \& Reichert, J. M. Development trends for human monoclonal antibody therapeutics. Nat. Rev. Drug Discov. 9, 767-774 (2010).

133. Sievers, E. L. \& Senter, P. D. Antibody-drug conjugates in cancer therapy. Annu. Rev. Med. 64, 15-29 (2013).

134. Benizri, S. et al. Bioconjugated oligonucleotides: recent developments and therapeutic applications. Bioconjug. Chem. 30, 366-383 (2019).

135. Anselmo, A. C. et al. Delivering nanoparticles to lungs while avoiding liver and spleen through adsorption on red blood cells. ACS Nano 7, 11129-11137 (2013)

136. Anselmo, A. C. \& Mitragotri, S. Cell-mediated delivery of nanoparticles: taking advantage of circulatory cells to target nanoparticles. J. Control. Release 190, 531-541 (2014).

137. Roberts, M. J., Bentley, M. D. \& Harris, J. M. Chemistry for peptide and protein PEGylation. Adv. Drug Deliv. Rev. 54, 459-476 (2002).

138. DeLoach, J. R. \& Sprandel, U. (eds) in Bibliotheca Haematologica Vol. 51 (Karger, 1985).

139. Stephan, M. T. \& Irvine, D. J. Enhancing cell therapies from the outside in: cell surface engineering using synthetic nanomaterials. Nano Today $\mathbf{6}$, 309-325 (2011).

140. Villa, C. H., Anselmo, A. C., Mitragotri, S. \& Muzykantov, V. Red blood cells: supercarriers for drugs, biologicals, and nanoparticles and inspiration for advanced delivery systems. Adv. Drug Deliv. Rev. 106, 88-103 (2016).

141. Song, W., Anselmo, A. C. \& Huang, L. Nanotechnology intervention of the microbiome for cancer therapy. Nat. Nanotechnol. 14, 1093-1103 (2019).

142. Ashmore-Harris, C. \& Fruhwirth, G. O. The clinical potential of gene editing as a tool to engineer cell-based therapeutics. Clin. Transl. Med. 9, 15 (2020)

143. Xu, X., Ho, W., Zhang, X., Bertrand, N. \& Farokhzad, O. Cancer nanomedicine: from targeted delivery to combination therapy. Trends $\mathrm{Mol}$. Med. 21, 223-232 (2015).

144. Bago, J. R. et al. Therapeutically engineered induced neural stem cells are tumour-homing and inhibit progression of glioblastoma. Nat. Commun. 7, 10593 (2016).

145. Pagliuca, F. W. et al. Generation of functional human pancreatic beta cells in vitro. Cell 159, 428-439 (2014).

146. Smith, T. T. et al. In situ programming of leukaemia-specific T cells using synthetic DNA nanocarriers. Nat. Nanotechnol. 12, 813-820 (2017).

147. Cheng, Q. et al. Selective organ targeting (SORT) nanoparticles for tissue-specific mRNA delivery and CRISPR-Cas gene editing. Nat. Nanotechnol. 15, 313-320 (2020).

148. Goldberg, M. S. Improving cancer immunotherapy through nanotechnology. Nat. Rev. Cancer 19, 587-602 (2019).

149. Song, W. et al. Synergistic and low adverse effect cancer immunotherapy by immunogenic chemotherapy and locally expressed PD-L1 trap. Nat. Commun. 9, 2237 (2018).

150. Shields, C. W. IV. et al. Cellular backpacks for macrophage immunotherapy Sci. Adv. 6, eaaz6579 (2020).

151. Cao, P. et al. Abstract 3577: application of deep IL-15 backpacks to human $\mathrm{T}$ cells demonstrates tunable loading with enhanced cell proliferation and antitumor activity. Cancer Res. 78(Suppl.), 3577 (2018).

152. Flanagan, T. Potential for pharmaceutical excipients to impact absorption: a mechanistic review for BCS class 1 and 3 drugs. Eur. J. Pharm. Biopharm. 141, 130-138 (2019).

153. Breda, S. A., Jimenez-Kairuz, A. F., Manzo, R. H. \& Olivera, M. E. Solubility behavior and biopharmaceutical classification of novel high-solubility ciprofloxacin and norfloxacin pharmaceutical derivatives. Int. J. Pharm. 371, 106-113 (2009).

154. Taniguchi, C., Kawabata, Y., Wada, K., Yamada, S. \& Onoue, S Microenvironmental $\mathrm{pH}$-modification to improve dissolution behavior and oral absorption for drugs with pH-dependent solubility. Expert Opin. Drug Deliv. 11, 505-516 (2014).

155. Lostalé-Seijo, I. \& Montenegro, J. Synthetic materials at the forefront of gene delivery. Nat. Rev. Chem. 2, 258-277 (2018).

156. Evans, B. C. et al. An anionic, endosome-escaping polymer to potentiate intracellular delivery of cationic peptides, biomacromolecules, and nanoparticles. Nat. Commun. 10, 5012 (2019). 
157. Hafez, I. M., Maurer, N. \& Cullis, P. R. On the mechanism whereby cationic lipids promote intracellular delivery of polynucleic acids. Gene Ther. 8, 1188-1196 (2001).

158. Wan, C., Allen, T. \& Cullis, P. Lipid nanoparticle delivery systems for siRNA-based therapeutics. Drug Deliv. Transl. Res. 4, 74-83 (2014).

159. Welling, S. H. et al. The role of citric acid in oral peptide and protein formulations: relationship between calcium chelation and proteolysis inhibition. Eur. J. Pharm. Biopharm. 86, 544-551 (2014).

160. Chen, S. et al. Dexamethasone prodrugs as potent suppressors of the immunostimulatory effects of lipid nanoparticle formulations of nucleic acids. J. Control. Release 286, 46-54 (2018).

161. Scarfo, I. \& Maus, M. V. Current approaches to increase CAR T cell potency in solid tumors: targeting the tumor microenvironment. J. Immunother. Cancer 5, 28 (2017).

162. Shum, T. et al. Constitutive signaling from an engineered IL7 receptor promotes durable tumor elimination by tumor-redirected T cells. Cancer Discov. 7, 1238-1247 (2017).

163. Berger, C. et al. Safety and immunologic effects of IL-15 administration in nonhuman primates. Blood 114, 2417-2426 (2009).

164. Lotze, M. T. et al. In vivo administration of purified human interleukin 2. II. Half life, immunologic effects, and expansion of peripheral lymphoid cells in vivo with recombinant IL 2. J. Immunol. 135, 2865-2875 (1985).

165. Yeku, O. O. \& Brentjens, R. J. Armored CAR T-cells: utilizing cytokines and pro-inflammatory ligands to enhance CAR T-cell anti-tumour efficacy. Biochem. Soc. Trans. 44, 412-418 (2016).

166. Di Stasi, A. et al. Inducible apoptosis as a safety switch for adoptive cell therapy. N. Engl. J. Med. 365, 1673-1683 (2011).

167. $\mathrm{Ma}, \mathrm{X}$. et al. Interleukin-23 engineering improves CAR $\mathrm{T}$ cell function in solid tumors. Nat. Biotechnol. 38, 448-459 (2020).

168. Hamilton, M. J., Weingarden, A. R., Unno, T., Khoruts, A. \& Sadowsky, M. J High-throughput DNA sequence analysis reveals stable engraftment of gut microbiota following transplantation of previously frozen fecal bacteria. Gut Microbes 4, 125-135 (2013).

169. Lee, S. \& Margolin, K. Cytokines in cancer immunotherapy. Cancers 3, 3856-3893 (2011).

170. Grayson, M. L. et al. Kucers' The Use of Antibiotics Sixth Edition: A Clinical Review of Antibacterial, Antifungal and Antiviral Drugs (CRC Press, 2010)

171. Dou, H. et al. Macrophage delivery of nanoformulated antiretroviral drug to the brain in a murine model of neuroAIDS. J. Immunol. 183, 661-669 (2009).

172. Brynskikh, A. M. et al. Macrophage delivery of therapeutic nanozymes in a murine model of Parkinson's disease. Nanomedicine 5, 379-396 (2010).

173. Mimee, M., Tucker, A. C., Voigt, C. A. \& Lu, T. K. Programming a human commensal bacterium, Bacteroides thetaiotaomicron, to sense and respond to stimuli in the murine gut microbiota. Cell Syst. 1, 62-71 (2015).

174. Charbonneau, M. R., Isabella, V. M., Li, N. \& Kurtz, C. B. Developing a new class of engineered live bacterial therapeutics to treat human diseases. Nat. Commun. 11, 1738-1738 (2020).

175. Robinson, J. R. \& Lee, V. H. (eds) Controlled Drug Delivery: Fundamentals and Applications (Dekker, 1987).

176. Owens, D. E. III \& Peppas, N. A. Opsonization, biodistribution, and pharmacokinetics of polymeric nanoparticles. Int. J. Pharm. 307, 93-102 (2006).

177. Tiwari, G. et al. Drug delivery systems: an updated review. Int. J. Pharm. Investig. 2, 2-11 (2012).

178. Kamaly, N., Yameen, B., Wu, J. \& Farokhzad, O. C. Degradable controlled-release polymers and polymeric nanoparticles: mechanisms of controlling drug release. Chem. Rev. 116, 2602-2663 (2016).

179. Rosen, H. \& Abribat, T. The rise and rise of drug delivery. Nat. Rev. Drug Discov. 4, 381-385 (2005).

180. Cole, E. T. et al. Enteric coated HPMC capsules designed to achieve intestinal targeting. Int. J. Pharm. 231, 83-95 (2002).

181. Carino, G. P. \& Mathiowitz, E. Oral insulin delivery. Adv. Drug Deliv. Rev. 35, 249-257 (1999).

182. Lane, M. E. Skin penetration enhancers. Int. J. Pharm. 447, 12-21 (2013).

183. Schwendeman, S. P., Shah, R. B., Bailey, B. A. \& Schwendeman, A. S. Injectable controlled release depots for large molecules. J. Control. Release 190, 240-253 (2014)

184. Awwad, S. \& Angkawinitwong, U. Overview of antibody drug delivery. Pharmaceutics 10, 83 (2018).

185. McKay, W. F., Peckham, S. M. \& Badura, J. M. A comprehensive clinical review of recombinant human bone morphogenetic protein-2 (INFUSE Bone Graft). Int. Orthop. 31, 729-734 (2007).

186. Geho, W. B., Geho, H. C., Lau, J. R. \& Gana, T. J. Hepatic-directed vesicle insulin: a review of formulation development and preclinical evaluation. J. Diabetes Sci. Technol. 3, 1451-1459 (2009).

187. Baselga, J. Clinical trials of Herceptin (trastuzumab). Eur. J. Cancer 37, 18-24 (2001)
188. Coats, S. et al. Antibody-drug conjugates: future directions in clinical and translational strategies to improve the therapeutic index. Clin. Cancer Res. 25, 5441-5448 (2019).

189. Verma, S. et al. Trastuzumab emtansine for HER2-positive advanced breast cancer. N. Engl. J. Med. 367, 1783-1791 (2012).

190. Gao, X. \& Huang, L. Cationic liposome-mediated gene transfer. Gene Ther. 2, 710-722 (1995)

191. Zelphati, O. \& Szoka, F. C. Mechanism of oligonucleotide release from cationic liposomes. Proc. Natl Acad. Sci. USA 93, 11493-11498 (1996).

192. Friend, D. S., Papahadjopoulos, D. \& Debs, R. J. Endocytosis and intracellular processing accompanying transfection mediated by cationic liposomes. Biochim. Biophys. Acta 1278, 41-50 (1996).

193. Nabel, G. J. et al. Direct gene transfer with DNA-liposome complexes in melanoma: expression, biologic activity, and lack of toxicity in humans. Proc. Natl Acad. Sci. USA 90, 11307-11311 (1993).

194. Filion, M. C. \& Phillips, N. C. Major limitations in the use of cationic liposomes for DNA delivery. Int. J. Pharm. 162, 159-170 (1998).

195. Lv, H., Zhang, S., Wang, B., Cui, S. \& Yan, J. Toxicity of cationic lipids and cationic polymers in gene delivery. J. Control. Release 114, 100-109 (2006).

196. Semple, S. C. et al. Efficient encapsulation of antisense oligonucleotides in lipid vesicles using ionizable aminolipids: formation of novel small multilamellar vesicle structures. Biochim. Biophys. Acta 1510, 152-166 (2001).

197. Semple, S. C. et al. Rational design of cationic lipids for siRNA delivery. Nat. Biotechnol. 28, 172-176 (2010).

198. Akinc, A. et al. The Onpattro story and the clinical translation of nanomedicines containing nucleic acid-based drugs. Nat. Nanotechnol. 14, 1084-1087 (2019)

199. Vegas, A. J. et al. Combinatorial hydrogel library enables identification of materials that mitigate the foreign body response in primates. Nat. Biotechnol. 34, 345-352 (2016).

200. Bochenek, M. A. et al. Alginate encapsulation as long-term immune protection of allogeneic pancreatic islet cells transplanted into the omental bursa of macaques. Nat. Biomed. Eng. 2, 810-821 (2018).

201. Grøndahl, L., Lawrie, G., Anitha, A. \& Shejwalkar, A. in Biointegration of Medical Implant Materials 2nd edn (ed. Sharma, C. P.) 375-403 (Woodhead Publishing, 2020).

202. Okita, K., Ichisaka, T. \& Yamanaka, S. Generation of germline-competent induced pluripotent stem cells. Nature 448, 313-317 (2007).

203. Carmona, G. et al. Correcting rare blood disorders using coagulation factors produced in vivo by Shielded Living Therapeutics products. Blood 134, 2065 (2019).

204. Stephan, S. B. et al. Biopolymer implants enhance the efficacy of adoptive T-cell therapy. Nat. Biotechnol. 33, 97-101 (2015).

205. Mao, A. S. et al. Programmable microencapsulation for enhanced mesenchymal stem cell persistence and immunomodulation. Proc. Natl Acad. Sci. USA 116, 15392-15397 (2019).

206. Lipsitz, Y. Y., Timmins, N. E. \& Zandstra, P. W. Quality cell therapy manufacturing by design. Nat. Biotechnol. 34, 393-400 (2016).

207. Malik, N. N. \& Durdy, M. B. in Translational Regenerative Medicine (eds Atala, A. \& Allickson, J. G.) 87-106 (Elsevier, 2015).

208. Ding, X. et al. High-throughput nuclear delivery and rapid expression of DNA via mechanical and electrical cell-membrane disruption. Nat. Biomed. Eng. 1, 0039 (2017).

209. Riley, R. S., June, C. H., Langer, R. \& Mitchell, M. J. Delivery technologies for cancer immunotherapy. Nat. Rev. Drug Discov. 18, 175-196 (2019).

210. Zhang, W.-W. et al. The first approved gene therapy product for cancer Ad-p53 (Gendicine): 12 years in the clinic. Hum. Gene Ther. 29, 160-179 (2018).

211. Devaud, C., John, L. B., Westwood, J. A., Darcy, P. K. \& Kershaw, M. H. Immune modulation of the tumor microenvironment for enhancing cancer immunotherapy. OncoImmunology 2, e25961 (2013).

212. Dane, K. Y. et al. Nano-sized drug-loaded micelles deliver payload to lymph node immune cells and prolong allograft survival. J. Control. Release 156, 154-160 (2011).

213. Eggermont, L. J., Paulis, L. E., Tel, J. \& Figdor, C. G. Towards efficient cancer immunotherapy: advances in developing artificial antigen-presenting cells. Trends Biotechnol. 32, 456-465 (2014).

214. Deshayes, S., Morris, M. C., Divita, G. \& Heitz, F. Cell-penetrating peptides: tools for intracellular delivery of therapeutics. Cell. Mol. Life Sci. 62, 1839-1849 (2005).

215. Adler, L. A. et al. Efficacy and safety of OROS methylphenidate in adults with attention-deficit/hyperactivity disorder: a randomized, placebo-controlled, double-blind, parallel group, dose-escalation study. J. Clin. Psychopharmacol. 29, 239-247 (2009).

216. Jana, S., Mandlekar, S. \& Marathe, P. Prodrug design to improve pharmacokinetic and drug delivery properties: challenges to the discovery scientists. Curr. Med. Chem. 17, 3874-3908 (2010). 
217. Swinney, D. C. \& Anthony, J. How were new medicines discovered? Nat. Rev. Drug Discov. 10, 507-519 (2011).

218. Chey, W. D. et al. Naloxegol for opioid-induced constipation in patients with noncancer pain. N. Engl. J. Med. 370, 2387-2396 (2014).

219. Agersø, H. et al. Pharmacokinetics and renal excretion of desmopressin after intravenous administration to healthy subjects and renally impaired patients. Br. J. Clin. Pharm. 58, 352-358 (2004).

220. Al-Tabakha, M. M. Future prospect of insulin inhalation for diabetic patients: the case of Afrezza versus Exubera. J. Control. Release 215, 25-38 (2015).

221. Booth, C. \& Gaspar, H. B. Pegademase bovine (PEG-ADA) for the treatment of infants and children with severe combined immunodeficiency (SCID). Biologics 3, 349-358 (2009).

222. Larsen, C. P. et al. Rational development of LEA29Y (belatacept), a high-affinity variant of CTLA4-Ig with potent immunosuppressive properties. Am. J. Transplant. 5, 443-453 (2005).

223. Pasut, G. Pegylation of biological molecules and potential benefits: pharmacological properties of certolizumab pegol. BioDrugs 28, 15-23 (2014).

224. Mensink, M. A., Frijlink, H. W., van der Voort Maarschalk, K. \& Hinrichs, W. L. How sugars protect proteins in the solid state and during drying (review): mechanisms of stabilization in relation to stress conditions. Eur. J. Pharm. Biopharm. 114, 288-295 (2017).

225. Sanford, M. Subcutaneous trastuzumab: a review of its use in HER2-positive breast cancer. Target. Oncol. 9, 85-94 (2014).

226. Cohenuram, M. \& Saif, M. W. Panitumumab the first fully human monoclonal antibody: from the bench to the clinic. Anti-cancer Drugs 18, 7-15 (2007).

227. $\mathrm{Hu}, \mathrm{Q}$. et al. in Development of Biopharmaceutical Drug-Device Products (eds Jameel, F. et al.) 343-372 (Springer International Publishing, 2020)

228. Eckstein, F. Phosphorothioates, essential components of therapeutic oligonucleotides. Nucleic Acid Ther. 24, 374-387 (2014).

229. Springer, A. D. \& Dowdy, S. F. GalNAc-siRNA conjugates: leading the way for delivery of RNAi therapeutics. Nucleic Acid Ther. 28, 109-118 (2018).

230. Corey, D. R. Nusinersen, an antisense oligonucleotide drug for spinal muscular atrophy. Nat. Neurosci. 20, 497-499 (2017).

231. $\mathrm{Xu}, \mathrm{L}$. et al. CRISPR-edited stem cells in a patient with HIV and acute lymphocytic leukemia. N. Engl. J. Med. 381, 1240-1247 (2019).

232. Brudno, J. N. \& Kochenderfer, J. N. Chimeric antigen receptor T-cell therapies for lymphoma. Nat. Rev. Clin. Oncol. 15, 31-46 (2018).

233. Bartlett, W. et al. Autologous chondrocyte implantation versus matrix-induced autologous chondrocyte implantation for osteochondral defects of the knee: a prospective, randomised study. J. Bone Joint Surg. Br. 87, 640-645 (2005).

234. Maude, S. L. et al. Tisagenlecleucel in children and young adults with B-cell lymphoblastic leukemia. N. Engl. J. Med. 378, 439-448 (2018).

235. Fordtran, J. S. \& Hofmann, A. F. Seventy years of polyethylene glycols in gastroenterology: the journey of PEG 4000 and 3350 from nonabsorbable marker to colonoscopy preparation to osmotic laxative. Gastroenterology 152, 675-680 (2017).

236. Abuchowski, A., van Es, T., Palczuk, N. C. \& Davis, F. F. Alteration of immunological properties of bovine serum albumin by covalent attachment of polyethylene glycol. J. Biol. Chem. 252, 3578-3581 (1977).

237. Liu, K.-J. \& Parsons, J. L. Solvent effects on the preferred conformation of poly(ethylene glycols). Macromolecules 2, 529-533 (1969).

238. Maxfield, J. \& Shepherd, I. Conformation of poly (ethylene oxide) in the solid state, melt and solution measured by Raman scattering. Polymer 16, 505-509 (1975).

239. Turecek, P. L., Bossard, M. J., Schoetens, F. \& Ivens, I. A. PEGylation of biopharmaceuticals: a review of chemistry and nonclinical safety information of approved drugs. J. Pharm. Sci. 105, 460-475 (2016).

240. Klibanov, A. L., Maruyama, K., Torchilin, V. P. \& Huang, L. Amphipathic polyethyleneglycols effectively prolong the circulation time of liposomes. FEBS Lett. 268, 235-237 (1990).

241. Rohlke, F. \& Stollman, N. Fecal microbiota transplantation in relapsing Clostridium difficile infection. Therap. Adv. Gastroenterol. 5, 403-420 (2012).

242. Li, W., Zhan, P., De Clercq, E., Lou, H. \& Liu, X. Current drug research on PEGylation with small molecular agents. Prog. Polym. Sci. 38, 421-444 (2013).

243. Yang, Q. \& Lai, S. K. Anti-PEG immunity: emergence, characteristics, and unaddressed questions. Wiley Interdiscip. Rev. Nanomed. Nanobiotechnol. 7, 655-677 (2015).

244. Mora, J. R., White, J. T. \& DeWall, S. L. Immunogenicity risk assessment for PEGylated therapeutics. AAPS J. 22, 35 (2020).

245. Wang, X., Ishida, T. \& Kiwada, H. Anti-PEG IgM elicited by injection of liposomes is involved in the enhanced blood clearance of a subsequent dose of PEGylated liposomes. J. Control. Release 119, 236-244 (2007).

246. Povsic, T. J. et al. Pre-existing anti-PEG antibodies are associated with severe immediate allergic reactions to pegnivacogin, a PEGylated aptamer. J. Allergy Clin. Immunol. 138, 1712-1715 (2016).

247. Bauer, M. et al. Poly (2-ethyl-2-oxazoline) as alternative for the stealth polymer poly (ethylene glycol): comparison of in vitro cytotoxicity and hemocompatibility. Macromol. Biosci. 12, 986-998 (2012).
248. Knop, K., Hoogenboom, R., Fischer, D. \& Schubert, U. S. Poly (ethylene glycol) in drug delivery: pros and cons as well as potential alternatives. Angew. Chem. Int. Ed. 49, 6288-6308 (2010).

249. Zhang, P. et al. Polypeptides with high zwitterion density for safe and effective therapeutics. Angew. Chem. Int. Ed. 57, 7743-7747 (2018).

250. Rodriguez, P. L. et al. Minimal "self" peptides that inhibit phagocytic clearance and enhance delivery of nanoparticles. Science 339, 971-975 (2013).

251. Sosale, N. G. et al. 'Marker of Self' CD47 on lentiviral vectors decreases macrophage-mediated clearance and increases delivery to SIRPA-expressing lung carcinoma tumors. Mol. Ther. Methods Clin. Dev. 3, 16080 (2016).

252. Shereen, M. A., Khan, S., Kazmi, A., Bashir, N. \& Siddique, R. COVID-19 infection: origin, transmission, and characteristics of human coronaviruses. J. Adv. Res. 24, 91-98 (2020).

253. Lipsitch, M., Swerdlow, D. L. \& Finelli, L. Defining the epidemiology of Covid-19-studies needed. N. Engl. J. Med. 382, 1194-1196 (2020).

254. Shin, M. D. et al. COVID-19 vaccine development and a potential nanomaterial path forward. Nat. Nanotechnol. 15, 646-655 (2020).

255. Chen, W. H., Strych, U., Hotez, P. J. \& Bottazzi, M. E. The SARS-CoV-2 vaccine pipeline: an overview. Curr. Trop. Med. Rep. 7, 61-64 (2020).

256. Le, T. T. et al. The COVID-19 vaccine development landscape. Nat. Rev. Drug Discov. 19, 305-306 (2020).

257. Florindo, H. F. et al. Immune-mediated approaches against COVID-19. Nat. Nanotechnol. 15, 630-645 (2020).

258. McHugh, K. J., Guarecuco, R., Langer, R. \& Jaklenec, A. Single-injection vaccines: progress, challenges, and opportunities. J. Control. Release 219, 596-609 (2015).

259. Arya, J. \& Prausnitz, M. R. Microneedle patches for vaccination in developing countries. J. Control. Release 240, 135-141 (2016).

260. Zaman, M., Chandrudu, S. \& Toth, I. Strategies for intranasal delivery of vaccines. Drug Deliv. Transl. Res. 3, 100-109 (2013).

261. Feldman, R. A. et al. mRNA vaccines against H10N8 and H7N9 influenza viruses of pandemic potential are immunogenic and well tolerated in healthy adults in phase 1 randomized clinical trials. Vaccine 37, 3326-3334 (2019).

262. Kose, N. et al. A lipid-encapsulated mRNA encoding a potently neutralizing human monoclonal antibody protects against chikungunya infection. Sci. Immunol. 4, eaaw6647 (2019).

263. Richner, J. M. et al. Modified mRNA vaccines protect against Zika virus infection. Cell 168, 1114-1125.e10 (2017).

264. Amante, D. H. et al. Skin transfection patterns and expression kinetics of electroporation-enhanced plasmid delivery using the CELLECTRA-3P, a portable next-generation dermal electroporation device. Hum. Gene Ther. Methods 26, 134-146 (2015).

265. McHugh, K. J. Employing drug delivery strategies to create safe and effective pharmaceuticals for COVID-19. Bioeng. Transl. Med. 5, e10163 (2020).

266. Singh, S. et al. Allogeneic cardiosphere-derived cells (CAP-1002) in critically ill COVID-19 patients: compassionate-use case series. Basic Res. Cardiol. 115, 36 (2020).

267. Har-Noy, M. \& Or, R. Allo-priming as a universal anti-viral vaccine: protecting elderly from current COVID-19 and any future unknown viral outbreak. J. Transl. Med. 18, 196 (2020).

\section{Acknowledgements}

A.M.V. was supported by the National Science Foundation Graduate Research Fellowship under grant number DGE-1650116. S.M. acknowledges support from the National Institutes of Health (1R01HL143806-01), the Department of Defense Medical Research and Development Program (W81XWH-19-2-0011) and the Defense Threat Reduction Agency (HDTRA1-15-1-0045). This publication was supported by the National Institute of General Medical Sciences of the National Institutes of Health under award number R35GM137898 (to A.C.A.). The content is solely the responsibility of the authors and does not necessarily represent the official views of the funding agencies.

\section{Author contributions}

All authors contributed to the discussion of the contents, and reviewed and edited the manuscript.

\section{Competing interests}

S.M. is a shareholder, advisor and board member of companies working in drug delivery. The other authors declare no competing interests.

\section{Additional information \\ Correspondence should be addressed to A.C.A. or S.M.}

Peer review information Nature Biomedical Engineering thanks Twan Lammers and the other, anonymous, reviewer(s) for their contribution to the peer review of this work.

Reprints and permissions information is available at www.nature.com/reprints. Publisher's note Springer Nature remains neutral with regard to jurisdictional claims in published maps and institutional affiliations.

(C) Springer Nature Limited 2021 